\title{
Ethical judgement and intent in business school students: the role of the psyche?
}

\section{Elaine Conway ${ }^{1} \cdot$ Yasuhiro Kotera $^{2}$}

Published online: 12 May 2020

(C) The Author(s) 2020

\begin{abstract}
The aim of this paper is to highlight how business schools can improve the ethical behaviour of future managers. It assesses the positions of ethical judgement and ethical intent within a sample of UK business students, together with an analysis of underlying explanatory factors to those positions, such as levels of depression, anxiety, stress, motivation and self-compassion. A range of scales were used to evaluate the ethical stance and psychological characteristics of a group of UK business students. The results indicate that feelings of selfcompassion, a sense of self-direction and mental health (in particular, depression) affect the ethical judgement and intent of students in a range of business and university scenarios. It is recommended that in addition to more formal ethics education, universities consider the mental health and psyche of their students to improve the efficacy of ethical training.
\end{abstract}

Keywords Ethics $\cdot$ Business students $\cdot$ Mental health $\cdot$ Self-compassion $\cdot$ Motivation

\section{Introduction}

Ethical issues in management and corporate scandals driven by unethical behaviour are never far away from the news headlines around the world. In the short term, such behaviour may increase profits and hence be seen as attractive financially. However, in the long run, firms with poor ethics tend to demonstrate weaker performance due to poor reputation (van Prooijen and Ellemers 2015) and increased business costs associated with lower productivity

Elaine Conway

e.conway@derby.ac.uk

1 Derby Business School, University of Derby, Kedleston Road, Derby DE22 1GB, UK

2 University of Derby Online Learning, Department of Psychology, Enterprise Centre, University of Derby, Derby DE1 3LD, UK 
and morale, such as higher staff, customer and supplier turnover (Crane and Matten 2016). It can also cause inefficient allocation of financial resources in economic markets (Fritzche 2005) and undermine share price (Cormier and Magnan 2017; Dean et al. 2010).

As a manager, navigating the modern, complex and competitive business world is undoubtedly challenging, with the expectation to deliver ever-improving results to shareholders yet having responsibilities to stakeholders outside the organisation, all whilst under increasing public scrutiny. This environment of constant pressure on managers to attend to the rising expectations of stakeholders can cause levels of stress to increase, standards of judgement to fall and unethical behaviour and practices to develop (Blodgett et al. 2001; Cohen et al. 2001). When facing issues where ethical judgement is required, where the interests of an individual or group are in conflict with the interests of another, this increasing pressure can cause managers to take decisions which are in conflict with expected norms and ethical behaviour for political reasons or in order to increase profits (Haski-Leventhal et al. 2017). Indeed, for as long as profitmaximisation remains the primary business motive, then ethical decision-making may struggle to gain much traction (McDonald 2004; McDonald and Donleavy 1995). If in the short term, there are no negative repercussions for the individual from that poor ethical decision, then it is more likely that that behaviour will continue and indeed worsen over time (Eweje and Brunton 2010). This unethical behaviour can manifest itself as abuses of power, acceptance or payment of bribes, fraud, corruption, misrepresenting the truth or abuse of confidentiality (Eweje and Brunton 2010; Holland and Albrecht 2013).

The question is: can these scandals be prevented by training future managers emerging from universities, by i) understanding what the causes of this behaviour might be, and ii) including more training in the business school curriculum to make business students more cognisant of good ethical behaviour? Business students are future managers and there is evidence that students who behave unethically in a university setting are more likely to behave unethically in other circumstances, such as in the world of work (Grimes 2012; Whitley and Keith-Spiegel 2001; Wright 2004, 2015). With the McCabe et al. (2006) study revealing that more than half of business students have acted dishonestly, and other studies (Barnett et al. 1994; Cohen et al. 2001; Cole and Smith 1996; Grimes 2012) finding that business students have lower ethical standards than established employees, this is clearly a concern. These low standards can manifest themselves in actual unethical behaviour, such as cheating; business students are more likely to cheat than those studying different disciplines (McCabe et al. 2006).

Whilst there have been numerous studies on ethics in university students (for example, (Adkins and Radtke 2004; Arain et al. 2017; Barnett et al. 1994; Borkowski and Ugras 1992; Chung et al. 2008; Cohen et al. 2001; Cole and Smith 1996; Cook et al. 2014; Eweje and Brunton 2010), there has been little attempt to understand the potential underlying causes to the apparent lower ethical standards in business students beyond age, gender and work experience. This paper adds to the literature by examining not only these aspects, over which business schools have arguably no influence, but by also evaluating the psyche, or psychological 'make-up' and mental health of students attracted to different careers within the business world. It also assesses how these aspects impact on their ethical judgement and potential ethical 
behaviour. With the criticism levelled at the current level and quality of ethics education in university business schools, this greater insight into the role of the psyche on ethical judgement and potential ethical behaviour (referred to as 'ethical intent' in the remainder of this paper) will allow business schools to re-evaluate their ethics provision to consider how they might incorporate the understanding of how their students 'tick' to improve its efficacy.

This paper is structured as follows: a literature review of the concepts of ethical judgement and ethical intent, the role of ethics education and the theories behind linkages between individual attributes and ethical judgement and intent; a methodology section which outlines the various scales used to obtain the data in the paper; results and discussion and conclusion.

\section{Literature review}

\section{What is ethical judgement and ethical intent?}

Ethical judgement is part of Jones' (1991) ethical decision-making model where it is part of a conscious process to assess which is the morally acceptable course of action to choose when making decisions with ethical impacts. These are situations where there are impacts on other people as a result of the decision (Cohen et al. 2001). Initially, an individual making such a decision has to be aware of the ethics of the situation ("ethical awareness') and then evaluate it ('ethical judgement'). This is followed by an intent to act ethically ('ethical intent') by prioritising the most ethical choice over the lesser. Finally, the behaviour deemed most acceptable to the wider community is carried out ('ethical behaviour') (Jones 1991). Since it is difficult to assess actual 'behaviour' ex ante, this paper evaluates the 'intent' to carry out ethical behaviour, rather than 'behaviour' per se. This ethical decision-making model follows similar ethical or moral decision-making models such those by Rest (1986) and Hunt and Vitell (1986). Jones (1991) acknowledged that the nature and impact of the decision to be made affects the decision itself (in other words, the same decision-making criteria are not blindly applied to all decisions). However, he also stressed the critical need for an individual to possess ethical or moral awareness, to recognise the ethical issues present in a situation as a prerequisite for ethical decision-making. Without this awareness, an individual is likely to make the decision according to some other criteria, such as economic rationality. That being the case, there is a need for raising this awareness to improve judgement and hence support more ethical decision-making (Lin et al. 2008).

\section{Teaching ethics - Ethical awareness}

Many business schools now offer ethics courses in an attempt to raise awareness of the importance of ethical decision-making (Arain et al. 2017; Cook et al. 2014; HaskiLeventhal et al. 2017; Holland and Albrecht 2013; Matten and Moon 2004). The influence of business schools can prove quite influential, with both positive and negative effects. Indeed, Arain et al. (2017) found that the behaviours and leadership of academic staff at business schools when interacting with their students was a key determinant to the ethical awareness or academic citizenship behaviour of students. By 
being role models of both good and poor ethical behaviour, they found that students do tend to replicate the good or poor behaviour themselves. Adkins and Radke (2004) found that students relied on faculty to teach them ethical behaviour to a greater extent that the academics themselves realised. This moral development of students by universities was also found by Hanson et al. (2017); interpersonal relationships between staff and students are very influential in reinforcing moral cultural identity, generating moral understanding and institutional moral behaviours: this holds across students in different international jurisdictions and in the workplace. Hence interventions (of good ethics) can help students who might be drawn to less ethical behaviour to reconsider their behaviour (Ferraro et al. 2005; Smyth and Davis 2004).

That notwithstanding, some elements of business school courses, for example economics modules can precipitate elevated levels of greed in some students (Wang et al. 2011). This was also a concern in the Holland and Albrecht (2013) study which indicated that business's orientation towards capitalism can engender a lack of focus on other critical issues such as the natural environment and business's impact on it. Others have agreed that whilst business schools still focus (like arguably many in the business world) on profit, not enough emphasis is placed on the value of the reputation of the firm such as the firm's social responsibilities (Cavanagh 2009).

Undoubtedly many business schools do attempt to make linkages between the responsibilities of business and its wider environment and society to educate their students on the impacts and social objectives businesses also have (Adkins and Radtke 2004; Holland and Albrecht 2013; Knotts et al. 2000). However, this can be a scattergun approach by inserting references to ethics topics quite superficially across the curriculum without any emphasis on a more structured approach (Swanson and Fisher 2008). Some schools prefer to have a more specific course dedicated to ethics, to make the messages about good business and behaviour more explicit (Floyd et al. 2013; Swanson and Fisher 2008). However, ethics training and its effectiveness are not universally supported.

Some professional bodies, such as the Association to Advance Collegiate Schools of Business (AACSB) in the US, have resisted the introduction of more formal ethics education in business schools (Floyd et al. 2013), despite opposition by college professors. This seems at odds with the feedback from the business world who would appear to prefer increased specific emphasis on ethics in business schools (Floyd et al. 2013). Holland and Albrecht's (2013) international survey of 211 scholars with business ethics expertise highlighted concerns about the curriculum of ethics and how to teach it adequately, faced with the increased prevalence of cheating and declining ethics in the business place. Two studies found that ethics courses had only a slight impact on students' ethical behaviour (Cohen et al. 2001; Waples et al. 2009), whilst another study found that business students continued to demonstrate the highest levels of cheating in comparison with other students even after ethics training (Lampe and Engleman-Lampe 2012).

Cole and Smith (1996) found that as students entered the workplace, their ethical judgement increased after interaction with other employees and experiencing the reality of the working environment, with its incumbent ethics policies and procedures. Whether this is a reflection of increased maturity or the tempering effect of seeing how the real business world acts (rather than being unduly influenced as a student by the media emphasis on the negative ethical actions of the business world) is open to 
conjecture (Cole and Smith 1996). Ethical judgement informs an individual's own behaviour but it also influences or justifies behaviours of other people (Gift et al. 2013; Leavitt et al. 2012). This is important in a business context as managers are under constant pressure to consider an ever-increasing number of stakeholders in their decision-making. The types of occupation identities or roles that people play in their professional lives undoubtedly has an influence on the moral behaviour of individuals in the work place (Leavitt et al. 2012). Their scope of concern and consequently their moral judgement is affected by these occupational identities and is tempered by interactions with others, in particular the sense of being accountable to others in the organisation (Leavitt et al. 2012). This human interaction is important to support corporate ethics policies: despite the whistleblowing in the Enron case, some studies have noted that even when they see unethical behaviour by others in the workplace, less than half of employees witnessing such behaviour would report it (Ethics Resource Center 1994). Professional societies also need to ensure that their standards of ethical behaviour are reinforced with personal interaction with other members, to reinforce professional body codes of conduct (Floyd et al. 2013); this is particularly influential to develop new (often younger) members of the profession whose behaviour might otherwise deviate from expected standards.

\section{Ethical judgement and the individual}

Each individual carries within them their own ethical or moral compass. This is as a result of the environment in which they are born, grow up and live, as influenced by culture, organisation and society (Jones 1991). People make ethical decisions based on the ideas of fairness, justice, duty, the sense of being for the greater good, which are often unpinned with philosophy or religious beliefs (Loo 2004).

Various studies have reviewed these individual-level characteristics with regard to ethical behaviour in areas such as gender, age, choice of programme of study/career choice and culture. Whilst undoubtedly culture plays a role in ethical judgement (Grimes 2012), it is not the intent of this study to focus on it, since it would be of limited use for business schools to assess their ethics education in the light of the myriad of cultural backgrounds their students hail from. Instead, this study extends the literature by reviewing other psychological traits of the individual which may transcend culture, such as their level of engagement, mental state, motivation and self-compassion, in short, their 'psyche'.

\section{Gender}

Previous studies on the association between ethics and gender have yielded mixed results. Some studies have found that females have more awareness of ethical issues (Barnett et al. 1994; Borkowski and Ugras 1998; Cohen et al. 2001; Cole and Smith 1996; Drover et al. 2012; Eweje and Brunton 2010; Haski-Leventhal et al. 2017; Ho et al. 2015). This is possibly because females may consider the broader issues of relationships and consider a more diverse range of decision rules when making ethical judgements (Galbraith et al. 1993). They may also have more compassion when faced with ethical decisions, whereas males may take such decisions based on rules, rights and individual justice (Gilligan 1982). However, other studies have not found any 
significant differences between ethical judgements in males and females (Kidwell et al. 1987; Serwinek 1992; Tsalikis and Ortiz-Buonafina 1990).

\section{Age}

Similarly, studies linking ethical judgement with age have produced mixed results. Whilst predominantly age appears to be positively correlated with better ethical awareness, moral development and behaviour for both managers and business students (Borkowski and Ugras 1992; Colby et al. 1983; Cole and Smith 1996; Ruegger and King 1992; Walker et al. 1987), these findings are not universal. Some studies have noted no discernible difference in ethical judgement across different age groups (Barnett et al. 1994; Christensen et al. 2016) and others have found that older respondents tend to display more conservative, strict and less compromising ethical behaviours (Longenecker et al. 1988; Serwinek 1992).

\section{Choice of subject major}

The choice of subject to study at university or the kind of person who is attracted to a particular course of study could be an influencing factor. There is some evidence that those studying in more caring professions have higher ethical standards than business students (Kotera et al. 2018a, 2018b), but within the subject area of business there are also differences in the kind of subjects studied, with some, like accounting for example, being more 'technical' than others. Indeed, Pascarella and Terenzini (2005) posited that the development of moral reasoning is likely to be slower in students of more technical disciplines such as accounting in comparison with those studying more liberal social sciences. Conversely, Gino and Ariely (2012) found that individuals with creative personalities (more likely to be in marketing or general business disciplines than accounting) tended to be more dishonest and more likely to cheat compared with less creative people. Hence the evidence on subject major with regard to the sub-disciplines of business is mixed; whilst Christensen et al. (2016) found that accounting students scored slightly higher for ethical judgement than other business students, two other studies found no significant differences at all (Borkowski and Ugras 1998; Cole and Smith 1996).

\section{Work experience}

As discussed previously, Cole and Smith (1996) have found that work experience does improve ethical judgement (also found by other studies, for example, (Christensen et al. 2016)). This is possibly due to increased maturity or by a change in the field of personal reference, since a student who has never worked formulates their opinion of the business world largely through the influence of the media who are more focused on the negative stories about business ethics rather than good examples. In contrast, someone who has worked will have experienced good practices as well (Cole and Smith 1996). Equally, by interacting with a wider group of people in a business context, supported by codes of ethics, people do tend to act more ethically (Sezer et al. 2015). 


\section{Psychological influences}

The role of the self in ethical decision-making is critical and studies on ethical judgement which do not consider it lack considerable depth of insight. Whilst an individual might insist that they always act ethically, the reality is often very different. Decisions to behave ethically or not can vary depending on personal characteristics such as situation or mood (Gelfand 2016; Gino and Shalvi 2015) and how we view ourselves and others (Tenbrunsel and Chugh 2015). Many of these personal facets are not static or indeed 'good or bad', however they do influence ethical behaviour. For example, an individual who is threatened or anxious is more likely to act in their own self-interest than someone who has a more positive self-view (Tenbrunsel and Chugh 2015).

The field of behavioural ethics is growing: there are numerous studies which examine the extent to which personality can influence ethical behaviour (Gino and Shalvi 2015), but other aspects, such as motivation, mental health, self-compassion and engagement, remain largely under-investigated with regard to ethical judgement and intent. In the case of mental health this is concerning, since the number of people with mental health issues is on the rise (Mental Health Foundation 2016). Although much of the field of behavioural ethics has remained within the psychology discipline, this paper seeks to move the debate across to the analysis of business ethics in the hope that by understanding a little more of the complexities of the human side of decision-making, that teachers of business ethics can more effectively tailor their ethics education.

\section{Methodology}

The aim of this study is to highlight how business schools can improve the ethical behaviour of future managers. It aims to assess the relationship between ethical judgement and ethical intent within a sample of UK business students and to evaluate any underlying causes for them by reviewing factors such as gender, age, country of origin (cultural influence), course of study and a variety of mental health or psychological markers, such as engagement, motivation and self-compassion. A paper-based questionnaire to measure these constructs was issued to a sample of business students (see below for description of sample). Ethical judgement and intent were measured by the use of the Multidimensional Ethics Scale (MES), engagement by the Utrecht Work Engagement Scale for Students (UWESS), mental health by the use of the Depression, Anxiety and Stress Scale 21 (DASS), motivation by the Academic Motivation Scale (AMS) and self-compassion with the Self-Compassion Scale (SCS). These scales have been developed by the academic and practitioner community as means to measure these constructs and each is described below.

\section{The multidimensional ethics scale (MES)}

First developed and later refined by Reidenbach and Robin $(1988,1990)$ following on from previous ethics scales, the purpose of the Multidimensional Ethics Scale (MES) is to capture the complexity implicit in the decision-making process when individuals make ethical judgements. Measures have been constructed to attempt to capture each 
rationale in the decision-making process where ethical judgement is required (Reidenbach and Robin 1990) and where the ensuing behaviour or actions cause harm or benefit to someone else (Jones 1991). This approach is intended to shed light on the reasons why a person believes what they do, rather than just understanding the belief itself. This is underpinned by the application of measures to probe five key ethical theories: justice theory, relativism, deontology, teleology (egoism) and teleology (utilitarianism). Justice theory is based on the premise that equals should be treated equally and unequals should be treated unequally, determined either based on equal shares for all, or divisions based on need, rights, efforts, contribution or merit according to whichever philosophy is applicable in a given situation (Reidenbach and Robin 1990). It also encompasses the concept of procedural justice where rules are developed in order to produce fair outcomes (Colby et al. 1983; Rest 1986). Relativism considers that for a given culture or person has their own set of normative beliefs; there is no universal set of beliefs which is acceptable to all (Reidenbach and Robin 1990). Deontology posits that each person has an obligation to consider and attend to the needs of others, based originally on the work of Kant (Reidenbach and Robin 1990). Teleology-based theories centre around the idea of the consequences (also referred to as consequentialist theories (Reidenbach and Robin 1990)) of an individual's actions and the moral issues associated with them. For egoism, this suggests an action is legitimate or ethical when the individual pursues actions which are to their own long-term benefit, since humans tend to act in their own self-interests. When the individual considers and acts to the benefit of wider society, this is referred to as utilitarianism and because the individual is weighing up which is the best outcome for the majority of people, this is deemed a more efficient result (Reidenbach and Robin 1990).

By developing the appropriate measures and testing their construct validity (that is, they intrinsically measure what they are intended to), the MES is a development from a simple (yes/no or good/bad) unidimensional approach considered in earlier ethics research (Cohen et al. 1993). It has since been tested and validated in a number of different scenarios, such as business students and leaders, accounting academics and in a number of different cultural contexts (Cohen et al. 1993; Lin et al. 2008; Loo 2004; McMahon and Harvey 2007; Nguyen and Biderman 2008; Reidenbach and Robin 1990). In the original MES, the main five philosophical theories were measured by justice scales, relativist scales, egoism scales, utilitarianism scales and deontology scales as depicted in Table 1. These scales are often merged slightly to create a moral equity construct (just-unjust, fair-unfair, morally rightnot morally right, acceptable to my family-not acceptable to my family), a relativist construct (culturally acceptable-not culturally acceptable, traditionally acceptable-not traditionally acceptable) and a social contract construct (violates an unspoken promise-does not violate an unspoken promise, violates an unwritten contract-does not violate an unwritten contract) (Loo 2004). There have been additional revisions and critiques to the MES (e.g.(Hyman 1996)) but they are still regarded as a comprehensive way of capturing the standards and beliefs within a population (Hyman 1996). However, like many questionnaire-based/self-reported data tools, they are not immune from social desirability bias (for example, 'I will respond how I think I ought to respond, rather than what I truly believe'). 
Table1 Judgement s (indicator variables) used for the philosophical latent variables within the Multidimensional Ethics Scale and the self/peer probability scales

\begin{tabular}{|c|c|c|c|c|c|c|c|c|c|c|c|}
\hline $\begin{array}{l}\text { Sub- } \\
\text { question } \\
\text { number }\end{array}$ & $\begin{array}{l}\text { Philosophical } \\
\text { scale (latent } \\
\text { variable) }\end{array}$ & Indicator variables & 1 & 2 & 3 & 4 & 5 & 6 & 7 & & $\begin{array}{l}\text { Cronbach's } \\
\text { alpha }\end{array}$ \\
\hline 1 & Justice & Fair & & & & & & & & Unfair & 0.722 \\
\hline 2 & Justice & Just & & & & & & & & Unjust & 0.721 \\
\hline 3 & Relativist & Acceptable & & & & & & & & Unacceptable & 0.709 \\
\hline 4 & Deontology & Morally right & & & & & & & & Morally wrong & 0.701 \\
\hline 5 & Deontology & Ethical & & & & & & & & Unethical & 0.750 \\
\hline 6 & Relativist & Traditionally acceptable & & & & & & & & Traditionally unacceptable & 0.833 \\
\hline 7 & Relativist & Culturally acceptable & & & & & & & & Culturally unacceptable & 0.808 \\
\hline 8 & Egotism & Self-promoting for me & & & & & & & & Not self-promoting for me & 0.842 \\
\hline 9 & Egotism & Personally satisfying for me & & & & & & & & Not personally satisfying for me & 0.818 \\
\hline 10 & Utilitarian & Produces the greatest utility & & & & & & & & Produces the least utility & 0.775 \\
\hline 11 & Utilitarian & $\begin{array}{l}\text { Maximises benefits while minimizes } \\
\text { harm }\end{array}$ & & & & & & & & $\begin{array}{l}\text { Minimises benefits while maximises } \\
\text { harm }\end{array}$ & 0.737 \\
\hline 12 & Deontology & Violates an unspoken promise & & & & & & & & Does not violate an unspoken promise & 0.723 \\
\hline \multirow[t]{3}{*}{13} & Deontology & Violates an unwritten contract & & & & & & & & Does not violate an unwritten contract & 0.751 \\
\hline & & & \multicolumn{6}{|c|}{ Low } & Hig & & \\
\hline & & & 1 & 2 & 3 & 4 & 5 & 6 & 7 & & \\
\hline 14 & Self-intent & $\begin{array}{l}\text { What is the probability you would do } \\
\text { it? }\end{array}$ & & & & & & & & & 0.812 \\
\hline 15 & Peer-intent & $\begin{array}{l}\text { What is the probability that others your } \\
\text { age would do it? }\end{array}$ & & & & & & & & & 0.819 \\
\hline
\end{tabular}

\section{Utrecht work engagement scale for students (UWESS)}

The Utrecht Work Engagement Scale for Students (UWESS), based on an original work-based model (Schaufeli and Bakker 2003) is comprised of three constructs Vigor, Dedication and Absorption - and is designed to measure engagement in academic studies as 'a positive and fulfilling work-related state of mind' (Schaufeli et al. 2002, p.74). Each construct is the sum of scores from a series of statements evaluated on a seven-point Likert scale to assess how students feel about and engage with their studies. The construct Vigor is assessed by six statements, Dedication by five statements and Absorption by six statements. The Cronbach alphas for the three subscales are Vigor 0.833 , Dedication 0.848 and Absorption 0.866 which demonstrate very good internal consistency (George and Mallery 2003).

Several previous studies (Cazan 2015; Maslach et al. 2001; Schaufeli et al. 2002; Seppälä et al. 2009; Siu et al. 2014; Wickramasinghe et al. 2018) have assessed both the validity and reliability of this scale in different jurisdictions and linked scores from this scale positively to student performance and negatively to burn-out (defined as an 'erosion of engagement' (Maslach et al. 2001, p.20). Lack of engagement can manifest itself by feelings of cynicism and detachment with work, and resultant sentiments of ineffectiveness and poor personal accomplishment (Maslach et al. 2001). In a managerial context, this can then result in poor ethical decisions being made (Keyko 2014) and is characterised by low energy (vigor), involvement/cynicism (dedication) and efficacy (absorption) (Bakker et al. 2004). Hence by reviewing engagement in this study we assess whether students have high levels of engagement to determine if there is a correlation with their ethical standpoint and intended behaviour.

\section{Depression, anxiety and stress scale 21 (DASS)}

The Depression Anxiety Stress Scale 21 (DASS) assesses the self-reported levels of depression, anxiety and stress that respondents feel, based on a four-point Likert scale 
which reports their levels of severity of feelings when recalling recent behaviour. These items are grouped into three sub-scales (depression, anxiety and stress) (Lovibond and Lovibond 1995). The Cronbach alphas for the questions in this scale were Depression 0.883 , Anxiety 0.832 and Stress 0.746 denoting good internal consistency.

Studies on the link between depression, anxiety, stress and ethical decision-making are scant: there is some evidence to support the theory that as individuals become depressed, anxious or feel overwhelmed by stress that their decision-making capacity is impaired (Pochard et al. 2001), which clearly has impacts on both ethics and the organisation for whom the decision is being made, although most research into depression, anxiety and stress has centred on the medical profession, psychology or medical students (Dyrbye et al. 2006).

\section{Academic motivation scale (AMS)}

The Academic Motivation Scale (AMS) developed by Vallerand et al. (1992) and since validated in different situations (for examples, see Cokley (2000) and Fairchild et al. (2005)) comprises of 28, seven-point Likert scale items to assess three different types of motivation: intrinsic motivation (further subdivided into intrinsic motivation to know, to accomplish and to experience stimulation), extrinsic motivation (subdivided into identified, introjected and regulation) and amotivation.

Intrinsic motivation (IM) is described as deriving pleasure and satisfaction from participating in an activity for its own sake rather than for some reward, stemming from individual self-determination (Deci and Ryan 1985; Vallerand et al. 1992). It is subcategorised into intrinsic motivation to know ('IM to know'), based on natural curiosity and the pleasure derived from learning something new, exploration or searching for meaning; intrinsic motivation to accomplish ('IM to accomplish'), driven by the desire to be competent, accomplished and achieving something and intrinsic motivation to experience stimulation ('IM for stimulation') where an individual derives pleasure from stimulating sensations from engaging in an activity, such reading an exciting book (Vallerand et al. 1992).

Extrinsic motivation (EM) relates to behaviours which individuals undertake as a means to an end, rather than for the intrinsic pleasure of the activity itself (Deci and Ryan 1985; Vallerand et al. 1992). It is subdivided into extrinsic motivation identified ('EM identified') where an individual believes the activity is important to them and they actively choose to undertake it because of a sense of it having value to achieve their own goals; extrinsic motivation introjected ('EM introjected') where an individual internalises the reasoning behind their actions, for example, 'I do this because I really should', and extrinsic motivation regulation ('EM regulation') because behaviour is regulated by force or reward, for example, 'I have been forced to do this' (Vallerand et al. 1992). A further concept is amotivation, where an individual perceives their behaviour to be caused by circumstances out of their own control, feeling both out of control and incompetent, which can result in them withdrawing from many activities, such as university enrolment (Deci and Ryan 1985; Vallerand et al. 1992).

The AMS evaluates these differing motivational concepts in a series of academic questions and this study uses the output to determine the levels in the student sample and to determine whether they may impact ethical judgement and intent. The 
Cronbach's alphas of all the questions in the AMS ranged between 0.725-0.845 indicating a high level of internal consistency.

\section{Self-compassion scale (SCS)}

Another element of personality is self-compassion or the ability to be kind and understanding to oneself when failure occurs or when in some difficulty, rather than being overly self-critical and over-analysing such occurrences (Neff 2003). There is some evidence that the ability to rationalise negative personal situations as part of a larger human condition (good things happen as well as bad things) rather than retaining and being defined by them reduces the likelihood of depression and anxiety and assists an individual to have a more positive outlook on life and regard others more positively (Neff 2003). This higher regard for oneself and others could positively impact an individual's ethical judgement as they are more likely to consider others when making conflicting decisions.

Both the original SCS and the short form (which was used in this study) were developed by Neff (2003) and have been validated in a number of scenarios for its construct and discriminate validity (for example, Garcia-Campayo et al. (2014) and Raes et al. (2011)). It comprises of 12, five-point Likert scale items ranging from 1 to 5. The Cronbach's alpha was 0.669 denoting a good level of internal consistency.

It is acknowledged that all question scales used in this study are self-reported perceptions and that there may be a tendency, as with all self-reported questionnaires, for respondents to answer what they think they should do (normative) rather than what they would do in reality (actual behaviour), as seen in social desirability bias (Latkin, Edwards, Davey-Rothwell, \& Tobin, 2017). Whilst this is an inherent weakness with this kind of questionnaire, it is accepted that valuable and valid insights may still be gained from such research with this caveat acknowledged (Subar et al. 2015).

\section{Sample description}

A paper-based questionnaire was distributed to a range of 144 business students in a post-1992 university in the UK Midlands during the first week of the new academic year. For some students, this was their first week at university, for others in later years of their programme this was a return to studies after the summer vacation or work placement. The total number of responses was reduced to 130 due to missing data. As well as the scales previously mentioned, the questionnaire comprised of background questions relating to the individual student (age, gender, course of study, year of study, country of origin, whether they worked as well as studied, and if so, for how many hours and whether they had sought help previously for any mental health issues). The demographics of the sample are illustrated in Table 2.

The sample was analysed by age, gender and business programme, where the respondent indicated a major area of study. Some students study joint honours programmes which do not have a dominant area of study as two subjects are studied equally; in this case, they were described as 'Other' in Table $2.38 \%$ of respondents studied Business as their major subject, 22\% Accounting, 17\% Marketing and the remaining $23 \%$ were classified as 'Other' with no defined subject major. Where respondents specified an answer, 62 classed as male and 63 classed as female, with 


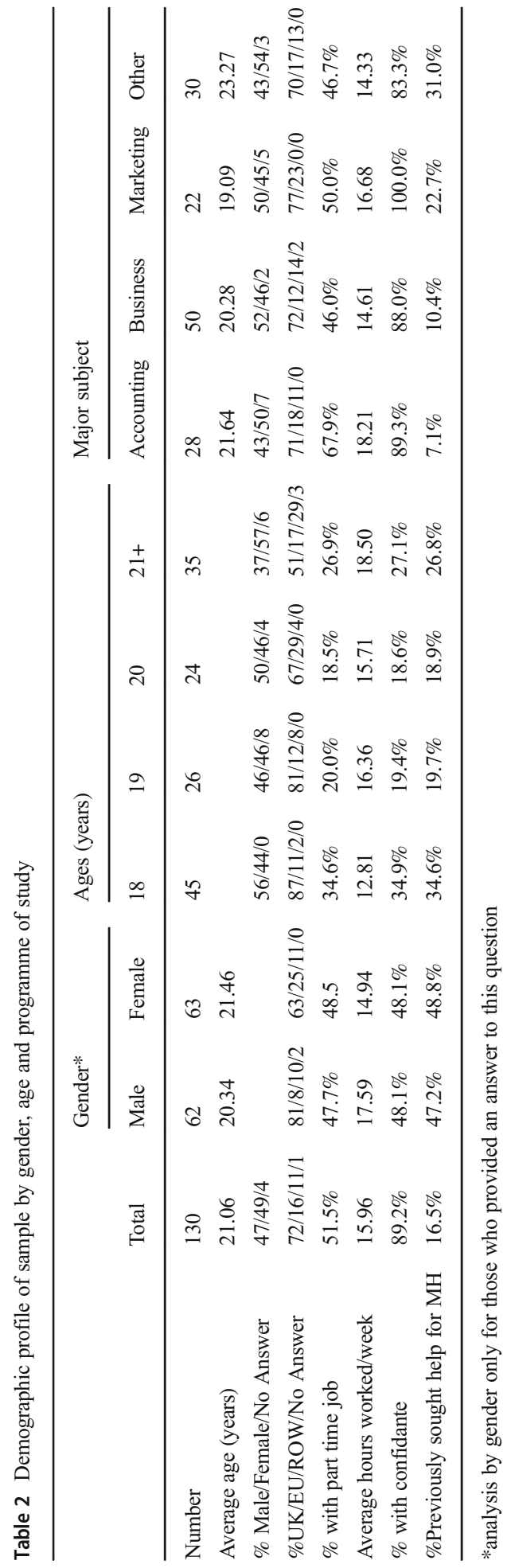


45 being 18 years of age (the usual age of starting university in the UK), 26 were 19, 24 were 24 and 35 were 21 years of age or greater. Given previous findings that those in work had different ethical attitudes to students (Cole and Smith 1996), respondents were asked whether they had a part time job in addition to studying and if they did work, how many hours per week on average did they work. Just over half (51.5\%) had a part time job and worked on average almost 16 hours a week on top of their studies. Depression and anxiety (the most common mental health issues (Mental Health Foundation 2016)) can cause feelings of detachment from others and hence impact on decision making where others are involved. Hence to test whether previous mental health issues could be a factor in ethical judgement respondents were asked if they had previously sought professional help for a mental health condition. $16.5 \%$ of respondents had previously sought professional help for mental health issues, which is in line with the Mental Health Foundation (2016) finding that $17 \%$ of the UK population over the age of 16 have exhibited a common mental health problem. The most commonly cited were depression and anxiety, although some were linked to bereavement and other physical medical problems (not all respondents detailed their previous issues).

Analysing by gender, the females were on average slightly older, (21.46 years versus 20.34 for male), however $25 \%$ of them were from EU countries (not including the UK) unlike only $8 \%$ for males. A similar percentage came from the rest of the world (ROW) for both genders. Slightly more women than men had a part time job, although they tended to work fewer hours per week (14.94 versus $17.59 \mathrm{~h}$ ). Only slightly more respondents with prior mental health issues were female which differs from national statistics which indicate that considerably more women than men have had diagnosable mental health conditions (Mental Health Foundation 2016).

By age, in general, older students tended to be female and more likely to be from outside the UK than younger students. Younger students were more likely to have a part time job, although the older students tended to work more hours per week on average ( $18.5 \mathrm{~h}$ compared with $12.8 \mathrm{~h}$ per week). Those aged 19 and 20 were slightly less likely to have a confidante or to have previously sought help with mental health issues previously.

The data was also analysed by programme, to assess whether students of a particular psychological make-up are more drawn to certain subjects and hence be reflected in their ethical judgement. Students without a defined subject major tended to be slightly older than those studying other subjects, particularly in comparison with Marketing students (average age 19). Analysing by gender, the majority of Business and Marketing students were male, whereas for Accounting and Other there were slightly more females (based on where an answer was provided to this question). Around $70 \%$ of all students were from the UK of origin irrespective of programme, although Marketing did not have any students from outside either the UK or the rest of Europe unlike the other programmes.

More than two-thirds of Accounting students did some kind of part time work, working on average more than $18 \mathrm{~h}$ per week on top of their studies. Half of Marketing students worked, working on average almost $17 \mathrm{~h}$ per week, whereas only around $46 \%$ of Business and Other students tended to have a part time job, and they worked on average fewer hours than the Accounting and Business students (approximately $14 \mathrm{~h}$ per week). 


\title{
The MES ethical judgement measures
}

In this paper, 12 scenarios were created, modified from examples in Emerson et al. (2007) and Jung (2009) as the basis for the MES. The first nine were a broad range of business-related ethical scenarios, and the last three were specifically student-orientated scenarios. Both work-based and university-based scenarios were tested to evaluate whether respondents would be more likely to behave unethically in a university setting rather than a work environment (McCabe et al. 2006). The perceptions of students in the Grimes' (2012) study felt that dishonesty in a business setting was less acceptable than in a university setting. These scenarios were designed to capture a range of ethical issues, from claiming inappropriate expenses to industrial espionage in a business context to plagiarism and vandalism in a student context (see full list of scenarios in Table 3). These scenarios were labelled the following for ease of reference:

\author{
- E1. Expenses \\ - E2. Emissions \\ - E3. Cash \\ - E4. Espionage \\ - E5. Bribery \\ - E6. Insider trading \\ - E7. Favouritism \\ - E8. Safety \\ - E9. Reporting \\ - E10. Plagiarism \\ - E11. Piracy \\ - E.12 Vandalism
}

Since the aim of the study is to assess both the ethical judgement and ethical intent of students, two questions were added to assess the likelihood of whether the respondent would replicate the behaviour in the scenario, or believed that a peer would do so. This had a seven-point Likert scale ranging from 1 (not probable that $\mathrm{I} / \mathrm{my}$ peers would do it) to 7 (highly probable that $\mathrm{I} / \mathrm{my}$ peers would do it). This personal intent and perception of peers' behaviour has been found in previous studies to differ: students' perceptions of what occurs in the business world were found to be quite negative, hence their lower expectations of behaviour, particularly of others (Cole and Smith 1996).

All questions were assessed for reliability using Cronbach's Alpha, which yielded scores between 0.701-0.842 as shown in Table 1, indicating good internal consistency of the questionnaire used. Each question was also individually reviewed to assess if this score would be substantially improved by deleting it, but there was no discernible benefit from removing any question, hence all were retained.

For each question, there were thirteen judgements as noted in Table 1, measured using a seven-point Likert scale. The responses from the individual respondents represent observed indicators of the latent (unobserved) variables used. From Reidenbach and Robin's MES (1988) model, these latent variables were represented by the scales for justice, relativist, egoism, utilitarian and deontological. In this study, there were 2 indicator variables for justice, 3 for relativist, 2 for egoism, 2 for utilitarian 
Table 3 Ethical scenarios for use with the Multidimensional Ethics Scale (MES) (adapted from Emerson et al. (2007) and Jung (2009)

Scenario Description (shortened title in brackets)

E1. A senior director who earns $£ 100,000$ per year claimed $£ 3000$ in expenses to which he was not entitled. The company he works for makes several million pounds in profit each year (Expenses).

E2. A general manager used a production process that exceeded legal environmental emissions limits in order to increase the profit of the company, as the company was under threat of bankruptcy (Emissions).

E3. A small business received one quarter of its annual revenue in cash, however the owner only reported half of this cash income for tax purposes (Cash).

E4. A company manager found that a competitor had made an important scientific discovery that would reducethe profits of his own company. He then hired a key employee from the competitor to learn the details of the discovery (Espionage).

E5. A company executive recognised that sending expensive Christmas gifts to purchasing managers in customer's companies might compromise their positions. However, he continued to send the gifts as it was common practice and stopping might result in loss of business (Bribery).

E6. A company director learned that his company was going to be taken over by another company and share prices were likely to rise. He purchased some shares and then sold them for a profit after the takeover went ahead (Insider trading).

E7. A company manager promoted a friend to a senior position in preference to a better-qualified manager whom he did not know (Favouritism)

E8. An engineer discovered a product design fault which could be a safety hazard. He told his company, but they chose not to do anything. The engineer decided to keep quiet, rather than take his complaint outside the company (Safety).

E9. A finance director chose a legal method of financial reporting which hid some embarrassing financial facts which otherwise would have become public (Reporting).

E10. A student was in a hurry to finish an assignment and forgot to note the sources of half of the ideas which she found on the internet. She decided to keep the ideas in her assignment but without citing where she got the information from (Plagiarism).

E11. A student purchased a computer with legal copies of software such as Microsoft Office, but could not afford to buy the licence for Adobe Photoshop which he really wanted, so he pirated a copy from a friend (Piracy).

E12. A student sees a classmate defacing a desk in a lecture room and videos it on her mobile phone. She attaches the video to a social media post. She did not inform the student that she had videoed the incident nor that she was going to post the video (Vandalism)

and 4 for deontological (see Table 1). Under the revised model (Reidenbach and Robin 1990) these would have represented 4 for a merged moral equity dimension, 3 for the relativist dimension and 2 for the deontological or contractualism dimension (Hansen 1992). Whilst under the 1990 model the teleological variables were omitted, Hansen reintroduced four teleological judgements as a combination of egoism and utilitarianism (Hansen 1992). Cohen et al. (1993) also retained these teleological judgements in their study. The argument for doing so is because it is understood that when faced with a range of alternative actions, individuals tend to consider both the element of deontology (the focus on the actions of an individual) and teleology (the consequences of those actions) (Hunt and Vitell 1986). Hence for this study, we have taken the broader range of 13 parameters as per the original Reidenbach and Robin (1988) study, in order to validate the model used on a broader scope of variables. 
To test the validity of the latent variables of justice, relativist, egoism, utilitarian and deontology, confirmatory factor analysis (CFA) was carried out using IBM SPSS AMOS (version 24.0.0.). A structured equation model was constructed linking the questions asked with the philosophical latent variables as per the structure in Table 1. As each measure (observed variable) only loaded onto one latent variable or construct, marker variables were used for each latent variable, loading them with a fixed loading of 1 to identify the model. The sample size was valid for the given number of parameters (Schreiber et al. 2006). The sample was also reviewed for outliers and multicollinearity. All variance inflation factors (VIFs) for the combined question scores were less than 2 which is deemed acceptable (Hair et al. 1998; O’Brien 2007).

In order to test each of the constructs, the regression weights were reviewed. For justice, all variables were significant to at least $p<0.05$, for relativist to at least $\mathrm{p}<$ 0.05 , for egoism all were significant to $p<0.01$ and for utilitarian all were significant to at least $p<0.05$. None of the variables were significant for the deontology variable. Whilst the underlying questions were retained in the study as they were still valid, the specific results for deontology as a variable were disregarded.

\section{Results and discussion}

The results of the MES are shown by question in Table 4 (work-based questions), Table 5 (university-based questions) and Table 6 (overall) analysed by total, gender, age and programme (major subject studied). To assist in interpretation, the table has been colour-coded to indicate green where respondents scored a vignette as the most unethical or unacceptable in the group of reference (e.g. by gender, age or programme) or red where they scored it as the most ethical or more acceptable, with graduations of colour between these two extremes. Regarding ethical intent, where the questions were asked whether respondents would behave in the same way as the people in the vignettes these were scored green when they felt they were least likely to act that way, and red if they were more likely (in comparison with the rest of the group). Equally, where respondents felt that their peers would be most likely to replicate the behaviour in the vignette, they were scored red and where least likely, scored green.

Generally, students did consider the behaviour in the vignettes to be unethical, with the scale ranging from 1 (ethical) to 7 (unethical), the average score across all vignettes was more than 4, but interestingly, unlike Grimes' (2012) study, students overall tended to consider the university-based behaviours as less ethical than the work-based behaviours. Students always believed that their peers were more likely to carry out the unethical behaviour than they themselves would (this finding agrees with Cole and Smith (1996)).

The highest scoring philosophical variables were egotism and justice across work-based, university-based and all scenarios together, indicating that students considered the behaviour presented as not self-promoting or satisfying for them, and that is was largely unfair and unjust. The least 'acceptable' work-based behaviour was E8 Safety and the most 'acceptable' was E6 Insider trading. Students were most likely to replicate E6 Insider trading and least likely to replicate E8 Safety and this was also their reflection of their peers' most and least 
Table 4 Score results of work-based scenarios by gender, age group and programme major

\begin{tabular}{|c|c|c|c|c|c|c|c|c|c|c|c|c|}
\hline \multirow[t]{2}{*}{ Work-based scenarios } & \multirow[b]{2}{*}{ Mean } & \multirow[b]{2}{*}{ Std. dev. } & \multicolumn{2}{|c|}{ Gender* } & \multicolumn{3}{|c|}{ Ages (years) } & \multirow[b]{2}{*}{$21+$} & & Major st & subject & \\
\hline & & & Male & Female & 18 & 19 & 20 & & Accounting & Business & Marketing & Other \\
\hline Number $(n=130)$ & & & 62 & 63 & 45 & 26 & 24 & 35 & 28 & 50 & 22 & 30 \\
\hline E1. Expenses & & & & & & & & & & & & \\
\hline Justice & 5.66 & 1.30 & 5.47 & 5.85 & 5.44 & 5.25 & 6.17 & 5.91 & 5.82 & 5.65 & 5.65 & 5.54 \\
\hline Relativist & 5.34 & 1.27 & 5.10 & 5.58 & 5.24 & 5.09 & 5.54 & 5.53 & 5.29 & 5.30 & 5.38 & 5.43 \\
\hline Egotism & 5.53 & 1.46 & 5.19 & 5.84 & 5.23 & 5.34 & 5.87 & 5.84 & 5.72 & 5.38 & 5.68 & 5.50 \\
\hline Utilitarian & 5.10 & 1.34 & 4.96 & 5.25 & 4.73 & 5.08 & 5.48 & 5.35 & 5.16 & 5.16 & 5.07 & 4.99 \\
\hline Self intent & 2.28 & 1.81 & 2.90 & 1.71 & 2.51 & 2.58 & 2.25 & 1.80 & 2.50 & 2.32 & 2.14 & 2.13 \\
\hline Peer intent & 4.34 & 1.51 & 4.42 & 4.26 & 4.47 & 4.38 & 4.67 & 3.92 & 4.46 & 4.42 & 4.41 & 4.04 \\
\hline E2. Emissions & & & & & & & & & & & & \\
\hline Justice & 5.49 & 1.39 & 5.35 & 5.59 & 5.27 & 5.35 & 5.71 & 5.71 & 5.98 & 5.22 & 5.43 & 5.51 \\
\hline Relativist & 5.60 & 1.15 & 5.46 & 5.77 & 5.47 & 5.44 & 5.71 & 5.82 & 6.12 & 5.49 & 5.50 & 5.39 \\
\hline Egotism & 5.56 & 1.34 & 5.29 & 5.77 & 5.52 & 5.33 & 5.99 & 5.47 & 6.08 & 5.19 & 5.70 & 5.57 \\
\hline Utilitarian & 5.06 & 1.43 & 4.77 & 5.36 & 5.02 & 4.92 & 5.21 & 5.10 & 5.54 & 4.82 & 4.89 & 5.14 \\
\hline Self intent & 2.18 & 1.55 & 2.40 & 1.99 & 2.18 & 2.58 & 2.08 & 1.96 & 1.68 & 2.52 & 2.41 & 1.91 \\
\hline Peer intent & 3.58 & 1.72 & 3.60 & 3.59 & 3.52 & 4.19 & 3.17 & 3.48 & 2.79 & 3.93 & 4.05 & 3.39 \\
\hline E3. Cash & & & & & & & & & & & & \\
\hline Justice & 6.03 & 1.12 & 5.76 & 6.31 & 5.92 & 5.61 & 6.31 & 6.30 & 6.21 & 5.97 & 5.93 & 6.05 \\
\hline Relativist & 5.60 & 1.27 & 5.27 & 5.98 & 5.67 & 5.24 & 5.75 & 5.67 & 5.77 & 5.66 & 5.38 & 5.50 \\
\hline Egotism & 5.74 & 1.41 & 5.36 & 6.12 & 5.74 & 5.35 & 5.81 & 5.97 & 5.95 & 5.49 & 5.75 & 5.95 \\
\hline Utilitarian & 5.15 & 1.47 & 4.87 & 5.46 & 5.10 & 5.10 & 4.94 & 5.39 & 5.00 & 5.12 & 5.02 & 5.43 \\
\hline Self intent & 1.98 & 1.53 & 2.47 & 1.46 & 1.91 & 2.31 & 2.04 & 1.80 & 2.14 & 2.08 & 1.86 & 1.77 \\
\hline Peer intent & 3.67 & 1.61 & 3.77 & 3.55 & 3.48 & 3.65 & 4.13 & 3.60 & 3.82 & 3.44 & 3.95 & 3.69 \\
\hline E4. Espionage & & & & & & & & & & & & \\
\hline Justice & 4.34 & 1.91 & 5.76 & 6.31 & 4.43 & 3.85 & 4.52 & 4.47 & 4.50 & 4.18 & 4.37 & 4.43 \\
\hline Relativist & 4.37 & 1.65 & 5.27 & 5.98 & 4.56 & 4.14 & 4.44 & 4.25 & 4.32 & 4.51 & 3.91 & 4.53 \\
\hline Egotism & 4.69 & 1.77 & 5.36 & 6.12 & 4.84 & 4.13 & 4.90 & 4.77 & 4.95 & 4.71 & 4.27 & 4.73 \\
\hline Utilitarian & 4.03 & 1.67 & 4.87 & 5.46 & 4.04 & 3.74 & 4.13 & 4.18 & 4.30 & 4.07 & 3.64 & 3.99 \\
\hline Self intent & 3.63 & 2.05 & 2.47 & 1.46 & 3.48 & 3.87 & 3.63 & 3.65 & 3.71 & 3.65 & 4.36 & 2.97 \\
\hline Peer intent & 4.57 & 1.80 & 3.77 & 3.55 & 4.39 & 4.60 & 4.92 & 4.53 & 4.82 & 4.27 & 5.36 & 4.24 \\
\hline E5. Bribery & & & & & & & & & & & & \\
\hline Justice & 4.27 & 1.62 & 3.99 & 4.57 & 3.90 & 3.63 & 4.48 & 5.08 & 4.55 & 4.25 & 3.58 & 4.57 \\
\hline Relativist & 3.98 & 1.51 & 3.82 & 4.17 & 3.82 & 3.60 & 3.99 & 4.48 & 4.23 & 4.17 & 3.29 & 3.96 \\
\hline Egotism & 4.50 & 1.61 & 4.29 & 4.67 & 4.36 & 4.00 & 4.85 & 4.81 & 4.86 & 4.52 & 4.12 & 4.42 \\
\hline Utilitarian & 4.43 & 1.46 & 4.14 & 4.74 & 4.38 & 4.02 & 4.33 & 4.88 & 4.64 & 4.41 & 4.39 & 4.31 \\
\hline Self intent & 3.36 & 1.81 & 3.71 & 3.09 & 3.25 & 3.90 & 3.42 & 3.08 & 3.69 & 3.23 & 3.77 & 2.99 \\
\hline Peer intent & 3.99 & 1.57 & 3.94 & 4.11 & 3.64 & 4.12 & 4.79 & 3.80 & 4.18 & 3.78 & 4.32 & 3.93 \\
\hline E6. Insider trading & & & & & & & & & & & & \\
\hline Justice & 3.37 & 1.76 & 3.08 & 3.62 & 3.12 & 3.02 & 3.40 & 3.94 & 3.39 & 3.39 & 2.87 & 3.68 \\
\hline Relativist & 3.55 & 1.60 & 3.37 & 3.74 & 3.44 & 3.38 & 3.38 & 3.95 & 3.52 & 3.81 & 2.98 & 3.56 \\
\hline Egotism & 3.79 & 1.78 & 3.41 & 4.18 & 3.73 & 3.03 & 4.04 & 4.27 & 3.84 & 3.71 & 3.64 & 4.01 \\
\hline Utilitarian & 3.38 & 1.59 & 3.11 & 3.65 & 2.92 & 3.50 & 3.58 & 3.75 & 3.55 & 3.31 & 2.77 & 3.80 \\
\hline Self intent & 4.39 & 1.99 & 5.06 & 3.80 & 4.79 & 4.62 & 4.38 & 3.71 & 4.36 & 4.56 & 4.77 & 3.85 \\
\hline Peer intent & 5.05 & 1.60 & 5.27 & 4.89 & 5.16 & 5.04 & 5.00 & 4.97 & 4.96 & 4.96 & 5.55 & 4.94 \\
\hline E7. Favouritism & & & & & & & & & & & & \\
\hline Justice & 5.70 & 1.47 & 5.63 & 5.75 & 5.52 & 5.58 & 5.60 & 6.09 & 5.57 & 5.43 & 6.06 & 6.00 \\
\hline Relativist & 5.17 & 1.61 & 5.22 & 5.10 & 5.07 & 5.22 & 5.07 & 5.32 & 4.83 & 5.01 & 5.59 & 5.42 \\
\hline Egotism & 5.24 & 1.62 & 5.09 & 5.33 & 5.26 & 4.96 & 5.19 & 5.46 & 5.04 & 5.05 & 5.43 & 5.61 \\
\hline Utilitarian & 5.44 & 1.38 & 5.43 & 5.43 & 5.17 & 5.38 & 5.19 & 6.00 & 4.99 & 5.27 & 5.70 & 5.94 \\
\hline Self intent & 2.56 & 1.59 & 2.82 & 2.29 & 2.86 & 2.88 & 2.58 & 1.93 & 2.75 & 2.87 & 2.59 & 1.85 \\
\hline Peer intent & 4.02 & 1.65 & 4.11 & 3.97 & 4.27 & 4.08 & 4.21 & 3.51 & 4.04 & 4.34 & 3.86 & 3.57 \\
\hline E8. Safety & & & & & & & & & & & & \\
\hline Justice & 5.74 & 1.42 & 5.56 & 5.93 & 5.63 & 5.44 & 5.50 & 6.26 & 5.68 & 5.57 & 6.04 & 5.85 \\
\hline Relativist & 5.69 & 1.26 & 5.45 & 5.92 & 5.57 & 5.52 & 5.59 & 6.02 & 5.57 & 5.69 & 5.80 & 5.71 \\
\hline Egotism & 5.91 & 1.27 & 5.78 & 6.06 & 5.76 & 5.84 & 5.63 & 6.37 & 5.80 & 5.72 & 6.16 & 6.17 \\
\hline Utilitarian & 6.06 & 1.15 & 6.03 & 6.13 & 5.99 & 6.03 & 5.90 & 6.30 & 5.84 & 6.11 & 6.16 & 6.13 \\
\hline Self intent & 1.79 & 1.37 & 2.10 & 1.46 & 1.75 & 1.96 & 1.83 & 1.69 & 1.96 & 1.74 & 1.73 & 1.76 \\
\hline Peer intent & 3.00 & 1.69 & 3.32 & 2.68 & 3.02 & 3.00 & 3.08 & 2.91 & 3.18 & 2.86 & 2.86 & 3.17 \\
\hline E9. Reporting & & & & & & & & & & & & \\
\hline Justice & 4.51 & 1.84 & 4.03 & 5.05 & 4.53 & 4.28 & 3.65 & 5.26 & 4.30 & 4.27 & 3.97 & 5.51 \\
\hline Relativist & 4.66 & 1.76 & 4.25 & 5.17 & 4.79 & 4.34 & 3.89 & 5.25 & 4.38 & 4.67 & 4.08 & 5.31 \\
\hline Egotism & 5.03 & 1.69 & 4.54 & 5.51 & 5.27 & 4.52 & 4.42 & 5.53 & 4.77 & 4.75 & 4.98 & 5.78 \\
\hline Utilitarian & 4.59 & 1.82 & 4.20 & 5.05 & 4.70 & 4.46 & 3.60 & 5.23 & 4.14 & 4.43 & 4.09 & 5.65 \\
\hline Self intent & 2.96 & 1.96 & 3.61 & 2.24 & 2.87 & 2.88 & 3.88 & 2.51 & 3.54 & 2.86 & 3.50 & 2.20 \\
\hline Peer intent & 3.91 & 1.73 & 4.15 & 3.65 & 3.66 & 3.65 & 4.96 & 3.71 & 4.39 & 3.66 & 4.18 & 3.70 \\
\hline Total work-based (E1-ES & & & & & & & & & & & & \\
\hline JusticeWB & 5.01 & 0.81 & 4.74 & 5.29 & 4.86 & 4.67 & 5.04 & 5.45 & 5.11 & 4.88 & 4.88 & 5.24 \\
\hline RelativistWB & 4.88 & 0.84 & 4.65 & 5.14 & 4.85 & 4.66 & 4.82 & 5.14 & 4.89 & 4.92 & 4.66 & 4.98 \\
\hline EgotismWB & 5.11 & 0.93 & 4.79 & 5.40 & 5.08 & 4.72 & 5.19 & 5.39 & 5.22 & 4.95 & 5.08 & 5.30 \\
\hline UtilitarianWB & 4.81 & 0.82 & 4.56 & 5.06 & 4.67 & 4.69 & 4.71 & 5.13 & 4.80 & 4.74 & 4.64 & 5.04 \\
\hline Self intentWB & 2.79 & 1.05 & 3.27 & 2.32 & 2.84 & 3.06 & 2.90 & 2.46 & 2.93 & 2.87 & 3.02 & 2.38 \\
\hline Peer intentWB & 4.01 & 0.99 & 4.14 & 3.91 & 3.96 & 4.08 & 4.32 & 3.83 & 4.07 & 3.96 & 4.28 & 3.85 \\
\hline
\end{tabular}

* analysis by gender only for those who provided an answer to this question

likely behaviours. For university-based scenarios, E12 vandalism was the least 'acceptable' and the behaviour least likely to be replicated either by the students themselves or their peers (in their opinion). E11 Piracy was the most 'acceptable' behaviour and most likely to be copied by the students or believed most likely for their peers to be copied. 
Table 5 Score results of university-based scenarios by total, gender, age group and programme major

\begin{tabular}{|c|c|c|c|c|c|c|c|c|c|c|c|c|}
\hline \multirow[t]{2}{*}{ University-based scenarios } & \multirow[b]{2}{*}{ Mean } & \multirow{3}{*}{ Std. dev. } & \multicolumn{2}{|c|}{ Gender ${ }^{*}$} & \multicolumn{3}{|c|}{ Ages (years) } & \multirow{4}{*}{${ }_{35}^{21+}$} & \multicolumn{4}{|c|}{ Major subject } \\
\hline & & & Male & Female & 18 & 19 & 20 & & Accounting & Business & Marketing & Other \\
\hline Number $(n=130)$ & & & 62 & 63 & 45 & 26 & 24 & & 28 & 50 & 22 & 30 \\
\hline \multicolumn{12}{|l|}{ E10. Plagiarism } & \\
\hline Justice & 5.25 & 1.27 & 5.10 & 5.48 & 4.91 & 4.71 & 5.00 & 6.24 & 5.29 & 5.30 & 5.05 & 5.27 \\
\hline Relativist & 5.38 & 1.23 & 5.26 & 5.56 & 5.17 & 4.94 & 5.24 & 6.09 & 5.69 & 5.33 & 5.29 & 5.23 \\
\hline Egotism & 5.50 & 1.38 & 5.23 & 5.83 & 5.39 & 4.85 & 5.46 & 6.17 & 5.77 & 5.37 & 5.48 & 5.50 \\
\hline Utilitarian & 5.32 & 1.43 & 5.17 & 5.48 & 4.94 & 4.88 & 5.42 & 6.07 & 5.64 & 5.43 & 4.70 & 5.28 \\
\hline Self intent & 2.16 & 1.59 & 2.23 & 2.08 & 2.51 & 2.54 & 1.67 & 1.78 & 2.04 & 2.14 & 2.27 & 2.24 \\
\hline Peer intent & 3.66 & 1.74 & 3.48 & 3.83 & 4.06 & 3.77 & 3.75 & 3.02 & 3.43 & 3.65 & 4.09 & 3.59 \\
\hline \multicolumn{13}{|l|}{ E11. Piracy } \\
\hline Justice & 5.14 & 1.55 & 4.79 & 5.48 & 5.17 & 4.88 & 4.77 & 5.54 & 4.79 & 5.06 & 5.39 & 5.42 \\
\hline Relativist & 4.90 & 1.61 & 4.52 & 5.29 & 5.04 & 4.87 & 4.47 & 5.05 & 4.77 & 5.02 & 4.88 & 4.84 \\
\hline Egotism & 4.98 & 1.73 & 4.35 & 5.51 & 5.12 & 4.62 & 4.25 & 5.57 & 4.89 & 4.86 & 4.86 & 5.35 \\
\hline Utilitarian & 4.53 & 1.63 & 4.08 & 5.00 & 4.31 & 4.53 & 4.25 & 5.02 & 4.34 & 4.61 & 4.16 & 4.85 \\
\hline Self intent & 3.30 & 2.05 & 4.08 & 2.66 & 3.21 & 3.50 & 3.83 & 2.92 & 3.61 & 3.45 & 3.55 & 2.61 \\
\hline Peer intent & 4.73 & 1.97 & 4.98 & 4.50 & 4.62 & 4.92 & 5.50 & 4.19 & 4.71 & 4.91 & 5.14 & 4.12 \\
\hline \multicolumn{13}{|l|}{ E12. Vandalism } \\
\hline Justice & 5.58 & 1.53 & 5.34 & 5.73 & 5.68 & 5.35 & 5.46 & 5.70 & 5.16 & 5.89 & 5.58 & 5.45 \\
\hline Relativist & 5.36 & 1.62 & 5.16 & 5.51 & 5.58 & 5.42 & 4.93 & 5.34 & 4.95 & 5.77 & 5.18 & 5.21 \\
\hline Egotism & 5.81 & 1.42 & 5.55 & 6.03 & 5.81 & 5.71 & 5.81 & 5.87 & 5.70 & 5.95 & 5.82 & 5.66 \\
\hline Utilitarian & 5.47 & 1.39 & 5.35 & 5.51 & 5.54 & 5.38 & 5.48 & 5.43 & 5.28 & 5.62 & 5.64 & 5.27 \\
\hline Self intent & 1.99 & 1.58 & 2.31 & 1.75 & 1.89 & 1.85 & 2.42 & 1.94 & 2.14 & 1.74 & 2.32 & 2.03 \\
\hline Peer intent & 3.84 & 1.89 & 3.90 & 3.80 & 3.49 & 3.85 & 4.92 & 3.54 & 4.18 & 3.50 & 4.23 & 3.79 \\
\hline \multicolumn{13}{|c|}{ Total university-based (E10-E12) } \\
\hline JusticeUB & 5.32 & 1.04 & 5.08 & 5.56 & 5.26 & 4.98 & 5.08 & 5.83 & 5.08 & 5.42 & 5.34 & 5.38 \\
\hline RelativistUB & 5.22 & 1.13 & 4.98 & 5.45 & 5.26 & 5.08 & 4.88 & 5.49 & 5.14 & 5.37 & 5.12 & 5.10 \\
\hline EgotismUB & 5.43 & 1.15 & 5.04 & 5.79 & 5.44 & 5.06 & 5.17 & 5.87 & 5.45 & 5.39 & 5.39 & 5.50 \\
\hline UtilitarianUB & 5.11 & 1.07 & 4.87 & 5.33 & 4.93 & 4.93 & 5.05 & 5.50 & 5.09 & 5.22 & 4.83 & 5.13 \\
\hline Self intentUB & 2.49 & 1.22 & 2.87 & 2.16 & 2.54 & 2.63 & 2.64 & 2.21 & 2.60 & 2.44 & 2.71 & 2.29 \\
\hline Peer intentUB & 4.08 & 1.41 & 4.12 & 4.04 & 4.05 & 4.18 & 4.72 & 3.58 & 4.11 & 4.02 & 4.48 & 3.84 \\
\hline
\end{tabular}

\section{Ethical judgement}

\section{Work-based scenarios}

Of all the work-based scenarios, whether divided by gender, age or programme, the least 'acceptable' behaviour was E8 Safety and the most 'acceptable' was E6 insider trading, with the exception of females who thought that E3 Cash and E4 Espionage were jointly the least 'acceptable'. This was also reflected in the likelihood that the students would replicate the scenarios - the one they deemed least acceptable they were least likely to do or think a peer would and similarly the one deemed most acceptable was the one they were most likely to do.

As Table 4 indicates, by gender almost universally, males regarded the behaviours in the vignettes as more acceptable than females, which is also reflected in many prior studies (for example, (Barnett et al. 1994; Borkowski and Ugras 1992; Drover et al. 2012). By age, with the exception of favouritism (E7) and to a lesser extent E1 where inappropriate expenses were claimed where 18-year olds were most accepting of poor ethical behaviour, 19-year olds were most likely to accept the poor ethical behaviour in the vignettes compared with older students. Why there should be a change between 18 and 19 years of age is not clear: possibly during the first year of university, students are more influenced by their schooling, which ebbs away when away from home for a year and they become more independent and have to interact with a wider variety of people and experiences than previously. Later in life (as evidenced by the older students) they consider ethics to be more important and necessary, then they tend to be less accepting of poor ethical behaviour (Christensen et al. 2016; Grimes 2012).

By programme, accountants tend to be less tolerant of those behaviours that impact the financial situation of the firm; they were less accepting of claiming inappropriate 
expenses (E1), exceeding environmental emissions (E2) (possibly due to financial impacts of fines that might be payable for environmental breaches), bribery (E5) and to a lesser extent not fully disclosing cash income (E3). They were however, more accepting of keeping health and safety issues quiet (E8) and favouritism (E7). Business students were more accepting of exceeding environmental emissions (E2) and to a lesser extent, favouritism (E7), but otherwise held a more median view of the ethical scenarios in comparison with their peers. Marketing students were more likely to regard the non-disclosure of health and safety issues (E8) as unacceptable, but were more tolerant of hiring a key employee away from a competitor to learn about their technology a competitor's discovery (E4), providing business gifts despite potentially compromising employee positions (E5), insider trading (E6) and hiding poor financial results from disclosure (E9).

For the marketing profession, where the pressure is often on gaining and retaining sales, what is considered ethical may well be different. These findings agree with some of Fritzsche and Becker's (1983) findings on marketing ethics which found that marketing professionals were least likely to act ethically when considering issues of coercion and control (most closely represented by the bribery (E5) vignette here) but most likely to act ethically when confronted by conflict of interest issues (not specifically tested in this current study). Equally, in their study of 395 marketing professionals across four different unethical marketing-based vignettes emulating the well-known four 'P's of marketing (Place, Promotion, Price and Product), Lund (2000) found that the professionals' behaviour varied depending on the ' $\mathrm{P}$ ' concerned. They were more likely to make ethical decisions about false advertising ('Promotion') and conflicts of interest ('Price') but less likely in cases of offering bribes ('Place') and personal integrity which involved hiding health and safety issues in a product ('Product'). The Lund study also found that women were slightly less tolerant of unethical behaviour than men although the influence of age was not consistent in the sample.

Students who did not specify or have a major subject of study were overall most likely to regard the behaviours in the vignettes as unethical.

In terms of the R\&R (1988) philosophical scales, students without a specified major subject were most likely to have a stronger sense of justice (equals being treated equally), relativism (understanding that others will have their own beliefs), egotism (understanding of when an action is in their own best interests) and utilitarianism (the ability to weigh up the impacts of decisions on wider society). It should be noted that this is regarding the judgements held on the behaviours in the vignettes, not necessarily the personality or behaviours of the individuals. Marketing students overall were least likely to demonstrate these ethical judgements.

\section{University-based scenarios}

The results of the university-based scenarios are in Table 5. Overall whether analysed by gender, age or programme, the least acceptable behaviour was E12 Vandalism and the least, E11 Piracy, with the exception of the oldest group of students and Accountants who believed E10 Plagiarism was the least acceptable. This was also reflected in their perceptions of whether they would carry out the activities or their peers would: the least acceptable behaviour was the one they were least likely to do (or believed their peers would) and vice versa. 
Table 6 Score results of all scenarios by total, gender, age group and programme major

\begin{tabular}{|c|c|c|c|c|c|c|c|c|c|c|c|c|}
\hline \multirow[t]{2}{*}{ Summary of scenarios } & \multirow{3}{*}{ Mean } & \multirow{3}{*}{ Std. dev. } & \multicolumn{2}{|c|}{ Gender ${ }^{*}$} & \multicolumn{4}{|c|}{ Ages (years) } & \multicolumn{4}{|c|}{ Major subject } \\
\hline & & & Male & Female & 18 & 19 & 20 & 21+ & Accounting & Business & Marketing & Other \\
\hline Number $(n=130)$ & & & 62 & 63 & 45 & 26 & 24 & 35 & 28 & 50 & 22 & 30 \\
\hline Total all scenarios (E1-E12) & & & & & & & & & & & & \\
\hline JusticeTot & 5.09 & 0.78 & 4.82 & 5.36 & 4.96 & 4.75 & 5.05 & 5.54 & 5.10 & 5.01 & 4.99 & 5.27 \\
\hline RelativistTot & 4.97 & 0.84 & 4.73 & 5.22 & 4.95 & 4.77 & 4.83 & 5.23 & 4.95 & 5.04 & 4.77 & 5.01 \\
\hline EgotismTot & 5.19 & 0.94 & 4.85 & 5.50 & 5.17 & 4.81 & 5.18 & 5.51 & 5.28 & 5.06 & 5.16 & 5.35 \\
\hline UtilitarianTot & 4.88 & 0.81 & 4.64 & 5.13 & 4.74 & 4.75 & 4.79 & 5.22 & 4.87 & 4.86 & 4.69 & 5.06 \\
\hline Self intentTot & 2.72 & 1.00 & 3.17 & 2.28 & 2.77 & 2.95 & 2.83 & 2.40 & 2.84 & 2.76 & 2.94 & 2.36 \\
\hline Peer intentTot & 4.03 & 0.99 & 4.13 & 3.94 & 3.98 & 4.10 & 4.42 & 3.77 & 4.08 & 3.98 & 4.33 & 3.85 \\
\hline
\end{tabular}

Similar to the work-based scenarios, the results indicate that males are more tolerant of unethical behaviour in comparison with females and older students are less tolerant than 19 and 20 year old students across the three vignettes. Across subjects, accountants are apparently more tolerant of plagiarism (E11), but least tolerant of vandalism (E12), whilst marketing students are more tolerant of most elements of unethical student behaviour. Both business students and those without a defined major subject are generally less tolerant of poor academic behaviour in comparison with the other two subject areas.

Similar results to the work-based scenarios were found across the philosophical scales and across the summary position of all scenarios as in Table 6 .

A review of the underlying indicator variables which made up the philosophical variables as presented in Table 7 also presents more detailed evidence that in general, females are less tolerant of poor ethical behaviour than men, older students are less tolerant than 19-year old students and students with no defined major subject are less tolerant of poor behaviour than marketing students.

\section{Ethical intent}

\section{Work-based scenarios}

The analysis of ethical intent (the responses to the question 'What is the probability you would do it?' ('Self intent')) and whether students believed their peers would behave as in the vignettes (responses to 'What is the probability that others your age would do it?' ('Peer intent')) is at the bottom of Tables 4-6 and is ranked between 1 (not likely) to 7 (very likely) (hence the red/green rating is reversed in comparison with the other questions in the tables). Overall, students were most likely to commit insider trading (E6) and believe that their peers would but least likely to hide health and safety issues (E8). Males were more likely to replicate all of the behaviours described in the workbased vignettes and more likely to believe that their peers would as well.

Accountants were more likely to replicate claiming inappropriate expenses (E1), not fully disclose cash receipts (E3), keep health and safety issues quiet (E8) and not disclose embarrassing financial facts (E9). They also were more likely to believe their peers would claim inappropriate expenses (E1), keep health and safety issues quiet (E8) and not disclose embarrassing financial facts (E9).

Business students were most likely to emulate the favouritism scenario (E7) and believed their peers would do so. Marketing students were most likely to hire a key employee away from a competitor to learn about their technology a competitor's 
discovery (E4), provide business gifts despite potentially compromising employee positions (E5), commit insider trading (E6) and hide poor financial results from disclosure (E9). They were most likely to believe their peers would do the same.

'Other' students were least likely overall to emulate the behaviours in the vignettes or believe their peers would.

\section{University-based scenarios}

Overall, students were most likely to copy the behaviour in the vandalism (E12) scenario and least likely to commit piracy (E11), whilst believing that their peers are most likely to commit piracy (E11) and least likely to plagiarise (E10).

Males are more likely than females to follow the unethical behaviour in the vignettes and to believe that their peers would, with the exception of plagiarism where women are more likely to believe their peers would commit it. Both genders are most likely to commit piracy (E11), males least likely to commit plagiarism (E10) and females least likely to replicate the vandalism scenarios (E12).

By age, 19 year-olds are most likely to commit plagiarism (E10) and to a lesser extent, emulate the vandalism behaviour (E12) whilst the older students are least likely to emulate any of the behaviours.

By subject area, accountants are least likely to commit plagiarism (E10), but more likely to commit piracy (E11). Marketing students appear most likely to commit all of the behaviours in comparison with their peers and most likely to believe their peers would. Business students appear least likely to plagiarise (E10) or emulate the vandalism behaviour (E12). Whilst those without a defined major subject are overall least likely to commit any of the behaviours or believe their peers would.

These findings are further supported by evidence across each of the indicator variables (e.g. fair, just etc.) as shown in Table 7.

\section{Individual demographics - Engagement, mental health, motivation and self-compassion}

In order to assess whether any of the psychological factors assessed could influence the ethical judgement or ethical intent of students, the results of the other scales discussed

Table 7 Score results of indicator variables by total, gender, age group and programme major

\begin{tabular}{|c|c|c|c|c|}
\hline \multirow[b]{2}{*}{ Indicator variables } & \multicolumn{2}{|c|}{ Total } & \multicolumn{2}{|c|}{ Gender* } \\
\hline & Mean & Std. dev. & Male & Female \\
\hline Fair & 5.06 & 0.80 & 4.81 & 5.3 \\
\hline Just & 5.12 & 0.79 & 4.84 & 5.3 \\
\hline Acceptable & 5.09 & 0.80 & 4.81 & 5.3 \\
\hline Morally right & 5.49 & 0.72 & 5.28 & 5.6 \\
\hline Ethical & 5.43 & 0.78 & 5.24 & 5.6 \\
\hline Traditionally acceptable & 4.91 & 1.02 & 4.69 & 5.1 \\
\hline Culturally acceptable & 4.90 & 0.94 & 4.70 & 5.1 \\
\hline Self-promoting & 5.15 & 0.99 & 4.79 & 5.4 \\
\hline Personally satisfying & 5.23 & 0.95 & 4.91 & 5.5 \\
\hline Greatest utility & 4.93 & 0.84 & 4.65 & 5.2 \\
\hline Maximises benefits & 4.83 & 0.85 & 4.63 & 5.0 \\
\hline Violates unspoken promise & 2.73 & 0.83 & 2.98 & 2.5 \\
\hline Violates unwritten contract & 2.73 & 0.86 & 2.99 & 2.4 \\
\hline Self intent & 2.72 & 1.00 & 3.17 & 2.2 \\
\hline Peer intent & 4.03 & 0.99 & 4.13 & 3.9 \\
\hline
\end{tabular}

\begin{tabular}{|l|l|}
\hline & \\
\hline 5.33 & 4.95 \\
5.39 & 4.97 \\
5.36 & 5.01 \\
5.69 & 5.30 \\
5.61 & 5.27 \\
5.17 & 4.94 \\
5.12 & 4.90 \\
5.48 & 5.09 \\
5.52 & 5.25 \\
5.22 & 4.74 \\
5.05 & 4.73 \\
2.50 & 2.88 \\
2.48 & 2.94 \\
2.28 & 2.77 \\
3.94 & 3.98 \\
\hline
\end{tabular}

Ages (years)

Major subject

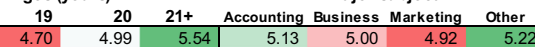

4.79
4.86

$5.30 \quad 5.53$

\begin{tabular}{|l|l|}
\hline 5.18 & 5.56 \\
\hline
\end{tabular}

\begin{tabular}{|l|l|}
\hline 4.75 & 4.72 \\
\hline 4.69 & 4.78 \\
\hline
\end{tabular}

\begin{tabular}{|l|l|}
\hline 4.69 & 4.78 \\
\hline 4.80 & 5.11 \\
\hline
\end{tabular}

$4.81 \quad 5.26$

$\begin{array}{ll}4.84 & 4.82 \\ 4.67 & 4.76\end{array}$

\begin{tabular}{l|l|}
4.97 & 4.76 \\
\hline & 2.63 \\
\hline
\end{tabular}

$2.96 \quad 2.61$

\begin{tabular}{l|l|}
2.95 & 2.83 \\
\hline 4.10 & 4.42 \\
\hline
\end{tabular}

\begin{tabular}{l|l|l|l|l|}
5.54 & 5.03 & 4.92 & 5.22 \\
5.43 & 5.08 & 5.03 & 5.07 & 5.32 \\
5.85 & 5.51 & 5.09 & 4.84 & 5.23 \\
5.72 & 5.58 & 5.32 & 5.32 & 5.59 \\
5.11 & 4.85 & 5.08 & 4.70 & 5.55 \\
5.14 & 4.87 & 4.93 & 4.78 & 4.82 \\
5.52 & 5.28 & 4.98 & 5.16 & 5.31 \\
5.50 & 5.28 & 5.14 & 5.15 & 5.39 \\
5.32 & 4.96 & 4.88 & 4.71 & 5.16 \\
5.13 & 4.78 & 4.85 & 4.67 & 4.97 \\
2.41 & 2.60 & 2.85 & 2.69 & 2.67 \\
2.36 & 2.64 & 2.80 & 2.76 & 2.66 \\
2.40 & 2.84 & 2.76 & 2.94 & 2.36 \\
3.77 & 4.08 & 3.98 & 4.33 & 3.85 \\
\hline
\end{tabular}


previously (UWESS, DASS, AMS and SCS) were analysed. The results by age, gender and subject area are in Table 8.

Females in this study score higher than males across all the individual attributes, with the exception of Vigor and Self-compassion. This means that whilst they are more dedicated and absorbed in their studies, and have both higher levels of intrinsic and extrinsic motivation, they are also likely to exhibit higher levels of depression, anxiety and stress and be harder on themselves (self-compassion) than their male counterparts.

Older students tend to exhibit greater engagement and motivation (both intrinsic and extrinsic) than their younger peers and to have greater self-compassion, whilst 18-year olds tend to be least motivated and 20-year olds exhibited the highest levels of depression, stress and anxiety: this latter finding could be due to concerns over final degree classification and future job prospects which loom largest in returning final year students (who tend to be aged around 20 when they begin their final year of study).

On average, Accounting students appear to demonstrate the lowest levels of Vigor (20.71), Dedication (21.25) and Absorption (16.25) in their studies than students of other subjects, however they also reported lower levels of depression (8.36), anxiety (9.00) and stress (13.57), particularly in comparison with Marketing students who demonstrated the highest scores $(13.45,16.91$ and 17.00 respectively). This may be due to accountants having a more predictable, stable and established career path than the more creative marketing career opportunities. Business and Other students scored consistently between the Accounting and Marketing students.

Intrinsic motivation was lowest in Accounting students and highest in Marketing students; yet Accounting students were more extrinsically motivated. This observation is true for all students: despite varying levels of the subcategories of intrinsic motivation and extrinsic motivation, the scores for extrinsic motivation were consistently higher than those for intrinsic motivation. In business students, this is not a surprise: they are more inherently driven by financial rewards rather than the reward of a more caring profession (Kotera et al. 2018a, 2018b). By contrast, Business students tended to have higher levels of self-compassion compared with Marketing students.

The output of these scales was then used in a series of regressions against both the philosophical variables (e.g. justice, relativist etc.) and indicator variables (fair, just etc.) discussed previously to determine any significant effects.

\section{Analysis of regressions}

Several ordinary least squares regressions were estimated, using the both the philosophical latent variables (e.g. justice, relativist etc.) and the subcomponent indicator variables (e.g. fair, just etc.) as dependent variables and then the personal demographics of the respondents as independent variables (e.g. age, gender, mental health, motivation etc.). This included regressions using the sub-categories of variables such as intrinsic motivation as well as the combined scores in different regressions (to avoid multicollinearity). The list of both dependent variables and independent variables is shown in Table 9.

The correlation matrix between all the variables is in Table 10. Whilst there are some significant correlations between a few of the variables, these largely occur where subcomponents are part of a higher-level variable, but these were not tested in the same 


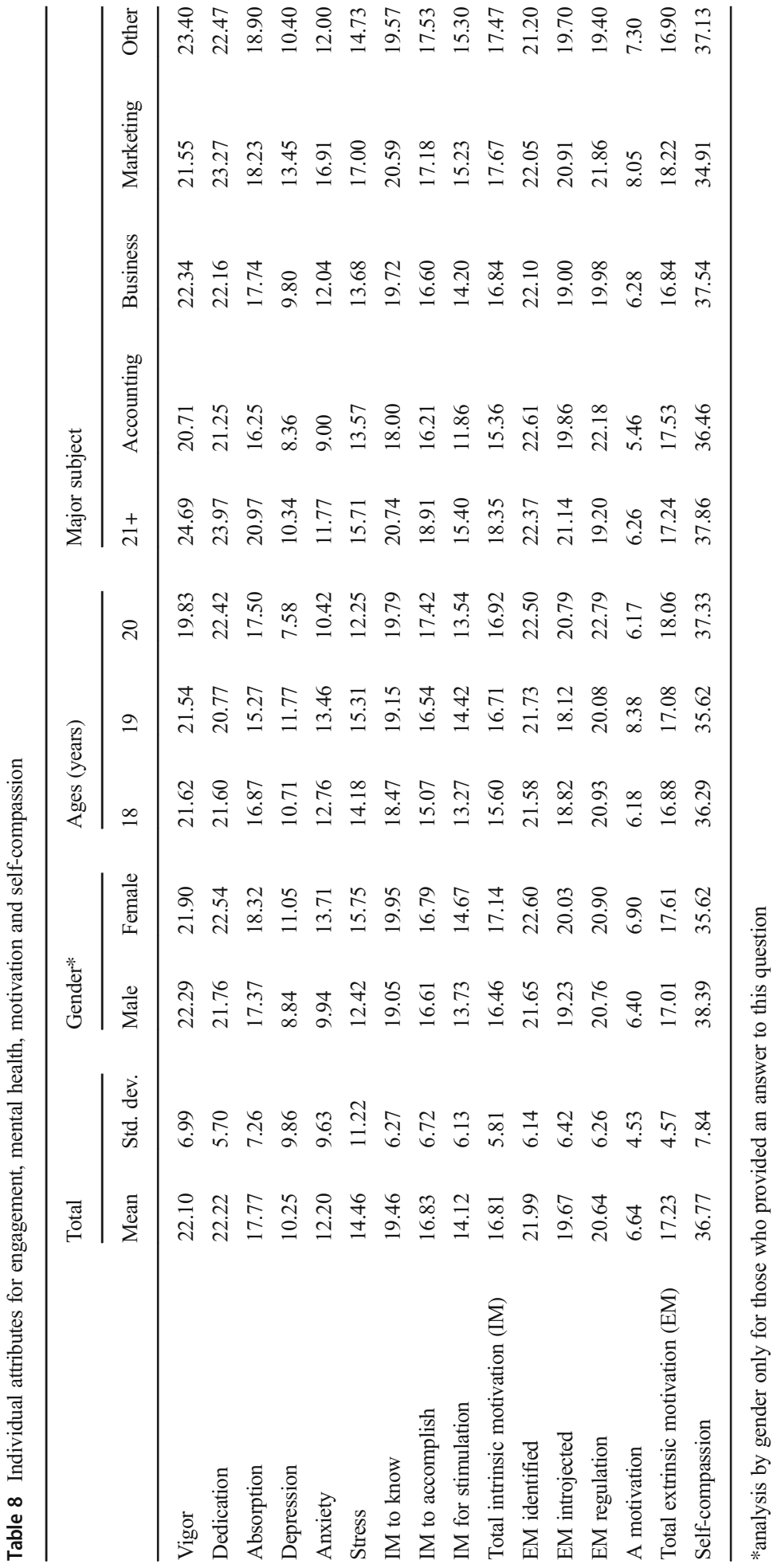


regression models. However, due to the large number of variables involved and the potential for over-specification of regression models, multi-collinearity and false results, a series of step regressions were estimated to ensure that the models used and hence results derived were the most efficient and meaningful. This approach uses only those independent variables which have an effect on the dependent variable and any that were above the level of statistical significance $p<0.05$ were omitted. All variance inflation factors (VIFs) were less than 2, which is below the acceptable upper threshold of 10 (Hair et al. 1998; O’Brien 2007).

Due to the large number of step regressions estimated, for brevity, a summary table of only those variables which were statistically significant is shown in Table 11, together with the direction of influence and the $\mathrm{R}$ squared and adjusted $\mathrm{R}$ squared statistics to assess model appropriateness.

\section{Ethical judgement and ethical intent}

Work-based scenarios For most of the work-based philosophical variables, gender and age had a significant and positive effect. Some elements of extrinsic motivation also had positive effects: extrinsic motivation identified (EM identified) (where individuals who undertake their activities because it is important to them) tends to increase relativism or a consideration of others' values. Equally, extrinsic motivation introjected (EM introjected) (where individuals rationalise their behaviours, for example 'I do this because I should') showed an increased tendency to believe their peers would act unethically: this may be a greater manifestation of lack of trust since where there is an element of compulsion or being forced to do something, it may result in an individual viewing others more negatively. One element of engagement, Vigor was negatively and significantly associated with Work-based Justice, although the reason behind this is not apparent. Anxiety tended to increase the likelihood that students would carry out the poor ethical behaviour and believe their peers would.

University-based scenarios Again, in the university-based scenarios, age and gender had some positive and significant effects. Unlike the work-based scenarios where extrinsic motivations had positive influence, two elements of intrinsic motivation, for satisfaction (IM to know) and to accomplish (IM to accomplish) had positive and significant effects on justice and egotism respectively. Hence those more motivated either by learning something new or for the sense of achieving something are more likely to show higher ethical judgement.

Indicator variables A summary review of the individual indicator variables (e.g. fair, just etc.) using step regressions against all of the demographic and psychological data as indicated in Table 12 shows more positive and negative psychological influences on evaluations of behaviour, with very little evidence at this more detailed level of the effects of gender and age. Higher levels of self-compassion (feeling good about oneself) has a positive and significant effect on the evaluation of fairness, justice, understanding of what is acceptable or morally correct and recognitions of whether the behaviour is self-promoting or personally satisfying; it has a negative effect on whether the individual is likely to replicate the behaviour. Depression has negative effects on fairness and whether an individual judges poor ethical behaviour to maximise the 
Table 9 List of dependent and independent variables used in different combinations of regression analysis

\begin{tabular}{ll}
\hline Regressions & \\
\hline Dependent variables & Independent variables \\
\hline Total Justice & Age \\
Relativist & Gender \\
Egotism & Country \\
Utilitarian & PT Work \\
Self Intent & Hours worked \\
Peer intent & Confidante \\
Work-based Justice & Previous Mental Health help \\
Relativist & Vigor \\
Egotism & Dedication \\
Utilitarian & Absorption \\
Self Intent & Depression \\
Peer intent & Anxiety \\
University-based Justice & Stress \\
Relativist & IM to know \\
Egotism & IM to accomplish \\
Utilitarian & IM for stimulation \\
Self Intent & Total IM \\
Peer intent & EM identified \\
Total Fair & EM introjected \\
Justice & EM regulation \\
Acceptable & Amotivation \\
Morally right & Total EM \\
Ethical & Self-Compassion \\
Traditionally acceptable & \\
Culturally accepted & \\
Self-promoting & \\
Personally satisfying & \\
Greatest utility & \\
Maximises benefits & \\
Violates an unspoken promise & \\
\hline & \\
\hline & \\
Vin unwritten contract & \\
\hline
\end{tabular}

benefits to the majority versus the minority in the given scenarios. Other negative effects include amotivation and understanding of what is morally correct and what is self-promoting or personally satisfying. Vigor has a positive and significant relationship with evaluating fairness.

In terms of motivations, extrinsic motivation regulation (EM regulation) has a positive correlation with evaluating justice and denoting what is culturally acceptable, extrinsic motivation identified (EM identified) has a positive correlation with self- 
器

产高旁

总高

焉

竞总

号兽

总.

离

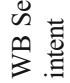

量

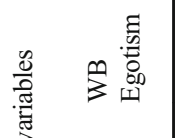

紊离

总

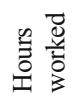

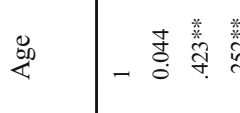

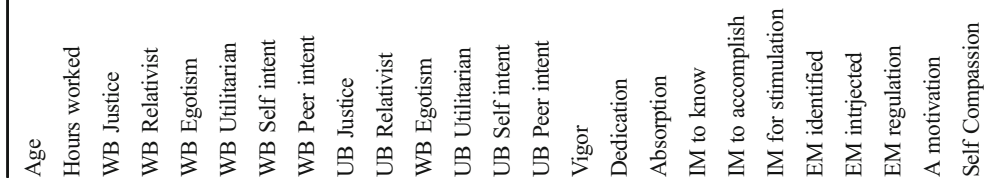

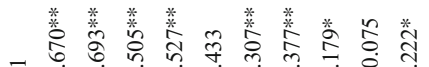

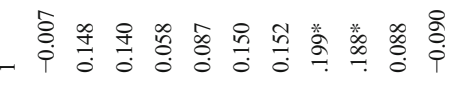

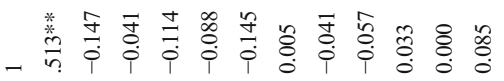

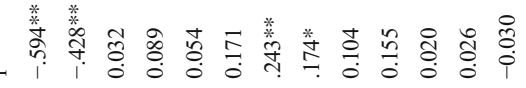

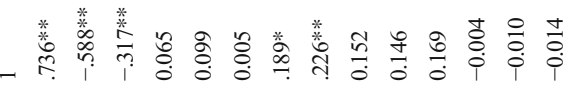

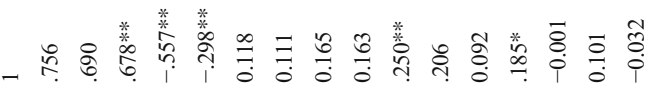

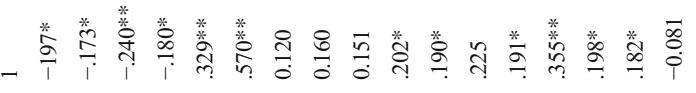

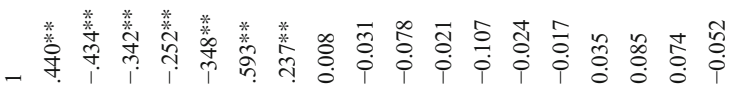

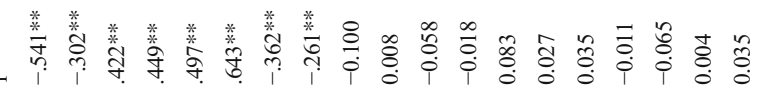

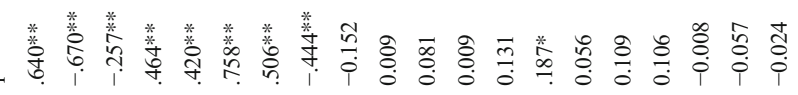

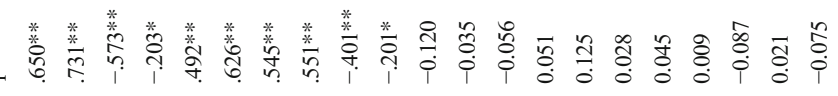

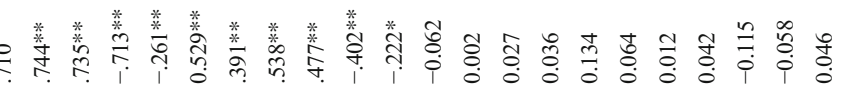

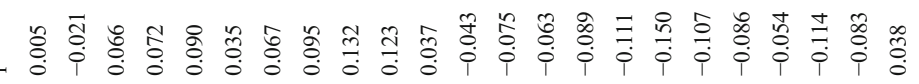

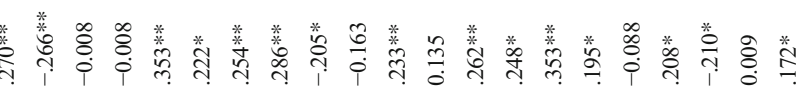




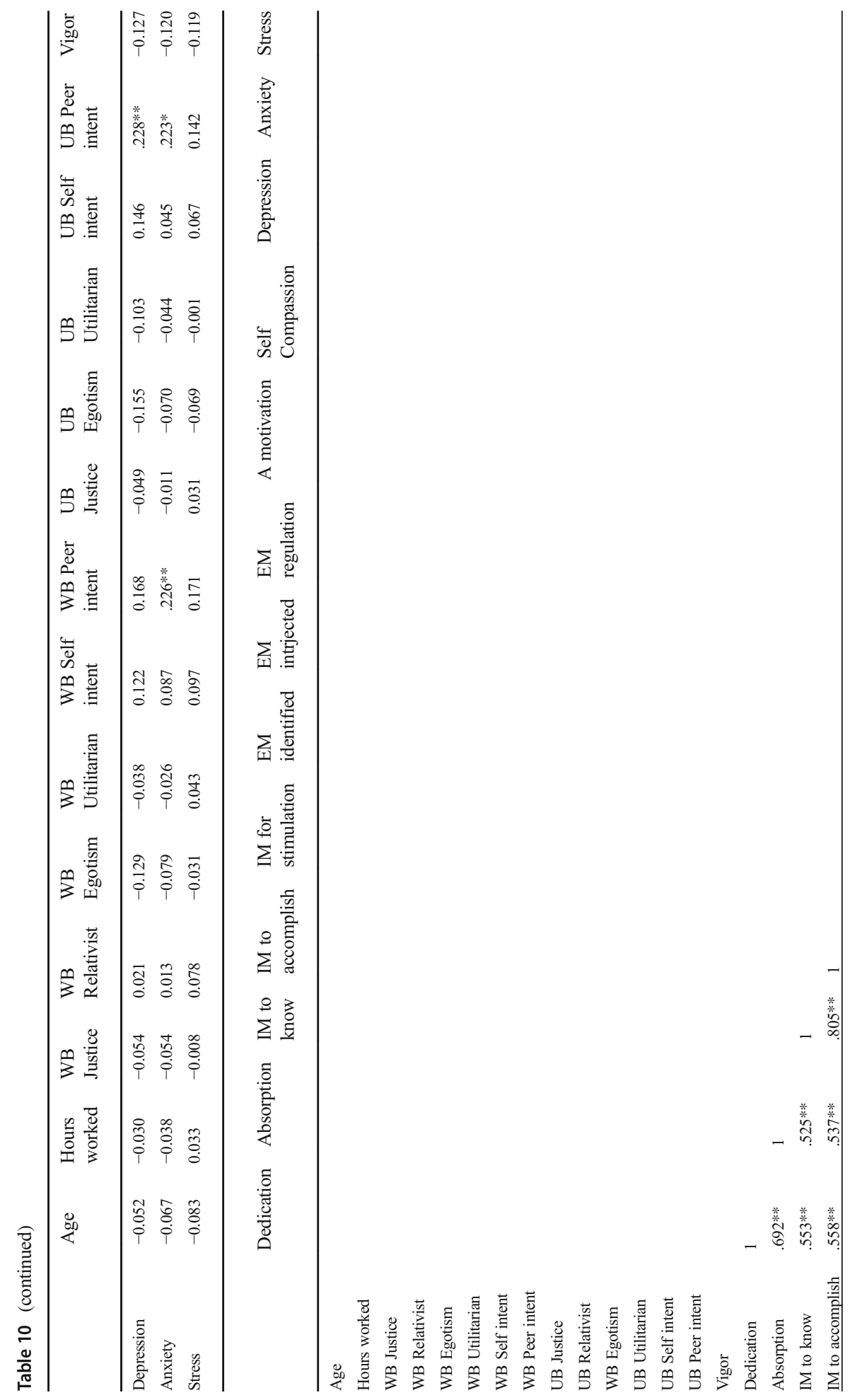




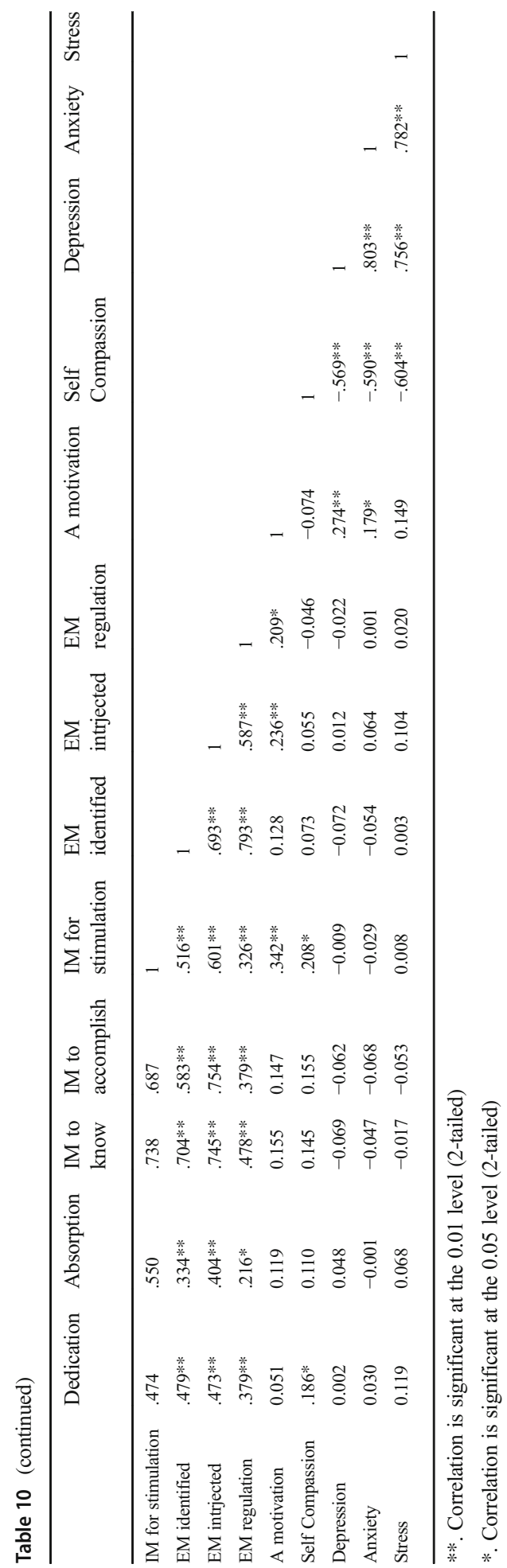


Table 11 Summarised results of 'philosophical' regressions with direction of impact, significance and R square of model

\begin{tabular}{|c|c|c|c|c|}
\hline Dependent variable & Independent variable & Correlation Sig. & $\mathrm{R}$ square & Adj. R sq \\
\hline \multirow[t]{2}{*}{ Work-based Justice } & Gender & Positive $\mathrm{p}<0.5$ & 0.238 & 0.224 \\
\hline & Age & Positive $p<0.1$ & & \\
\hline \multirow[t]{3}{*}{ Relativist } & Age & Positive $\mathrm{p}<0.1$ & 0.156 & 0.133 \\
\hline & Vigor & Negative $p<0.1$ & & \\
\hline & EM identified & Positive $\mathrm{p}<0.5$ & & \\
\hline \multirow[t]{2}{*}{ Egotism } & Gender & Positive $\mathrm{p}<0.1$ & 0.166 & 0.151 \\
\hline & Age & Positive $\mathrm{p}<0.1$ & & \\
\hline \multirow[t]{2}{*}{ Utilitarian } & Gender & Positive $\mathrm{p}<0.5$ & 0.112 & 0.096 \\
\hline & Age & Positive $p<01$ & & \\
\hline \multirow[t]{4}{*}{ Self intent } & Gender & Negative $\mathrm{p}<0.1$ & 0.264 & 0.237 \\
\hline & Age & Negative $p<0.1$ & & \\
\hline & Programme & Negative $p<0.5$ & & \\
\hline & Anxiety & Positive $p<0.5$ & & \\
\hline \multirow[t]{3}{*}{ Peer Intent } & Gender & Negative $\mathrm{p}<0.5$ & 0.196 & 0.174 \\
\hline & EM introjected & Positive $\mathrm{p}<0.1$ & & \\
\hline & Anxiety & Positive $\mathrm{p}<0.5$ & & \\
\hline \multirow[t]{2}{*}{ University-based Justice } & Age & Positive $\mathrm{p}<0.1$ & 0.167 & 0.152 \\
\hline & IM to know & Positive $\mathrm{p}<0.5$ & & \\
\hline Relativist & Age & Positive $\mathrm{p}<0.5$ & 0.055 & 0.046 \\
\hline \multirow[t]{2}{*}{ Egotism } & Gender & Positive $\mathrm{p}<0.1$ & 0.14 & 0.124 \\
\hline & IM to accomplish & Positive $\mathrm{p}<0.1$ & & \\
\hline Utilitarian & Age & Positive $\mathrm{p}<0.1$ & 0.079 & 0.071 \\
\hline Self Intent & Gender & Negative $p<0.1$ & 0.093 & 0.085 \\
\hline \multirow[t]{2}{*}{ Total Justice } & Gender & Positive $\mathrm{p}<0.5$ & 0.266 & 0.253 \\
\hline & Age & Positive $\mathrm{p}<0.1$ & & \\
\hline \multirow[t]{3}{*}{ Relativist } & Age & Positive $\mathrm{p}<0.1$ & 0.154 & 0.131 \\
\hline & EM identified & Positive $\mathrm{p}<0.5$ & & \\
\hline & Vigor & Negative $\mathrm{p}<0.1$ & & \\
\hline \multirow[t]{2}{*}{ Egotism } & Gender & Positive $\mathrm{p}<0.1$ & 0.173 & 0.158 \\
\hline & Age & Positive $\mathrm{p}<0.1$ & & \\
\hline \multirow[t]{4}{*}{ Self Intent } & Gender & Negative $p<0.1$ & 0.268 & 0.241 \\
\hline & Age & Negative $\mathrm{p}<0.1$ & & \\
\hline & Programme & Negative $\mathrm{p}<0.5$ & & \\
\hline & Depression & Positive $\mathrm{p}<0.1$ & & \\
\hline \multirow[t]{3}{*}{ Peer Intent } & Gender & Negative $p<0.5$ & 0.177 & 0.155 \\
\hline & EM introjected & Positive $\mathrm{p}<0.1$ & & \\
\hline & Anxiety & Positive $\mathrm{p}<0.5$ & & \\
\hline
\end{tabular}

promotion. Only intrinsic motivation to accomplish (IM to accomplish) is positively and significantly correlated with personal satisfaction. 
The only gender effect indicated that females were less likely to replicate the poor ethical behaviour: there were no other effects of gender or age at this more detailed level of analysis. Hence there are indications that psychological and mental health aspects do affect the evaluations of ethical behaviour and to a lesser extent of ethical intent when evaluated at this level, but the nuances of it may be lost when reviewed at a higher level.

Self-compassion in particular appears to be a key positive psychological marker to ethical judgement and intent and it is in particular this element, together with amotivation and depression (for negative impacts) that business schools should be aware of: by encouraging their students to be more self-compassionate, to gain a greater sense of being in control over what they do and what happens to them and to improve their mental health may well result in better ethical judgement and intent. Whilst universities may not be able to influence intrinsic and extrinsic motivations to study, they could move some of their ethics teaching towards this better self-awareness and more robust mental health. Having a more positive outlook on life can lead to individuals regarding others more positively (Neff 2003). This in turn could improve ethical awareness and potentially behaviour by taking more consideration of others in decision-making as an individual is more likely to consider the impacts on others that they view more positively than negatively.

Table 12 Summarised results of 'indicator variable' regressions with direction of impact, significance and R square of model

\begin{tabular}{|c|c|c|c|c|}
\hline Dependent variable & Independent variable & Correlation Sig. & $\mathrm{R}$ square & Adj. R sq \\
\hline \multirow[t]{3}{*}{ Fair } & Self-compassion & Positive $\mathrm{p}<0.5$ & 0.696 & 0.639 \\
\hline & Vigor & Positive $\mathrm{p}<0.1$ & & \\
\hline & Depression & Negative $\mathrm{p}<0.5$ & & \\
\hline \multirow[t]{2}{*}{ Just } & Self-compassion & Positive $\mathrm{p}<0.1$ & 0.596 & 0.548 \\
\hline & EM regulation & Positive $\mathrm{p}<0.1$ & & \\
\hline Acceptable & Self-compassion & Positive $\mathrm{p}<0.1$ & 0.371 & 0.336 \\
\hline \multirow[t]{2}{*}{ Morally Right } & Self-compassion & Positive $\mathrm{p}<0.5$ & 0.369 & 0.295 \\
\hline & Amotivation & Negative $\mathrm{p}<0.5$ & & \\
\hline \multirow[t]{2}{*}{ Culturally acceptable } & EM regulation & Positive $\mathrm{p}<0.1$ & 0.574 & 0.524 \\
\hline & IM for stimulation & Negative $\mathrm{p}<0.1$ & & \\
\hline \multirow[t]{3}{*}{ Self promoting } & Self-compassion & Positive $\mathrm{p}<0.1$ & 0.62 & 0.549 \\
\hline & EM identified & Positive $\mathrm{p}<0.1$ & & \\
\hline & Amotivation & Negative $\mathrm{p}<0.5$ & & \\
\hline \multirow[t]{4}{*}{ Personally satisfying } & IM to accomplish & Positive $\mathrm{p}<0.1$ & 0.74 & 0.671 \\
\hline & Self compassion & Positive $\mathrm{p}<0.1$ & & \\
\hline & Prof help & Positive $\mathrm{p}<0.5$ & & \\
\hline & Amotivation & Negative $\mathrm{p}<0.5$ & & \\
\hline Maximises benefits & Depression & Negative $\mathrm{p}<0.1$ & 0.481 & 0.453 \\
\hline \multirow[t]{2}{*}{ Self Intent } & Self-compassion & Negative $p<0.1$ & 0.547 & 0.494 \\
\hline & Gender & Negative $\mathrm{p}<0.5$ & & \\
\hline
\end{tabular}




\section{Conclusion and future research}

There is some acknowledgement that more exposure to ethics education would be beneficial, so that students have a greater appreciation of good ethical behaviour and the intrinsic value inherent in it, instead of being driven by more extrinsic rewards (Borkowski and Ugras 1998). However, the efficacy of ethics education has also been called into question (Cohen et al. 2001). In order to understand how business schools might best support their students in their ethics education, it is important to understand the students themselves. Like the findings in Hunt and Vitell (1986) and Jones (1991), the students in this sample (and within that, males and females, age groups and subjectmajors) did vary both their ethical judgement and intent according to the situation in each vignette (Jones 1991). There was clearly a teleological process in which students evaluated the scale and impact of each vignette against their internal values to determine the degree to which it demonstrated 'good' or 'bad' behaviour and whether they would emulate it. For example, those vignettes with higher impact (e.g. E8 Safety), which had greater corporate consequences if they occurred or were detected tended to be scored as more unethical than those that had lower perceived impact (such as E6 Insider trading (even though clearly illegal and relatively easy to detect)). Unlike the Grimes (2012) study, overall students found the university-based scenarios less 'acceptable' than the work-based ones, perhaps as university was the main term of reference for the respondents as only approximately half also worked. This is despite the belief that there is a lower standard of accountability in the university setting than in the 'real world' (Grimes 2012).

However, age, gender, choice of subject-major and work experience (and culture, which was not reviewed in this study beyond the country of origin of respondents and which did not demonstrate a statistically significant effect) cannot be readily be altered by business schools' ethics education. This study found that self-compassion, an improvement in the sense of self-direction (counter to amotivation) and mental health (in particular, depression) influenced the perspectives of the students in this study. Hence what is needed in ethics education is a different approach which takes into account the psychological make-up and mental health (or psyche) of the student cohort in order to improve the consideration of others in their decision-making. For example, an individual who is threatened or anxious is more likely to act in their own self-interest than someone who has a more positive self-view (Tenbrunsel and Chugh 2015). This might necessitate a more cross-disciplinary approach to boost the self-compassion and mental health of the individual first, prior to the actual teaching of ethics. It is hence a recommendation from this research that business schools place more importance on improving the awareness of self-compassion, self-belief and mental health in its students to support them in potentially better ethical judgement and future ethical behaviour.

This study has some limitations which must be acknowledged but which could be overcome by future research: it evaluated a relatively small sample of students from only one UK university in a given year. There may be trends that emerge over time or in different institutions across the world with regard to psychology and ethics remains to be seen. For example, the university in question was also classed as a 'post-1992' university, denoting its emphasis on more applied teaching and for a more inclusive cohort of students. Research should be carried out in a range of institutions to determine 
whether the psyche and approach to ethics of these students is different from those in other more traditional and research-oriented institutions. Likewise, longitudinal studies are needed to ascertain the causal direction of these constructs.

Whether or not universities provide formal ethics training to their business students, this research indicates that the consideration of ethics in decision-making can be diluted where students' psyche and mental health are not considered. Therefore, it may be beneficial for educational institutions to address these aspects of their students to support their appreciation of the impacts of their actions and to strengthen their ethical awareness in decision-making.

Open Access This article is licensed under a Creative Commons Attribution 4.0 International License, which permits use, sharing, adaptation, distribution and reproduction in any medium or format, as long as you give appropriate credit to the original author(s) and the source, provide a link to the Creative Commons licence, and indicate if changes were made. The images or other third party material in this article are included in the article's Creative Commons licence, unless indicated otherwise in a credit line to the material. If material is not included in the article's Creative Commons licence and your intended use is not permitted by statutory regulation or exceeds the permitted use, you will need to obtain permission directly from the copyright holder. To view a copy of this licence, visit http://creativecommons.org/licenses/by/4.0/.

\section{References}

Adkins, N., and R.R. Radtke. 2004. Students' and faculty members' perceptions of the importance of business ethics and accounting ethics education: Is there an expectations gap? Journal of Business Ethics 51 (3): 279-300. https://doi.org/10.1023/B:BUSI.0000032700.07607.02.

Arain, G.A., A. Sheikh, I. Hameed, and M.A. Asadullah. 2017. Do as I do: The effect of teachers ethical leadership on business students' academic citizenship behaviors. Ethics and Behavior 27 (8): 665-680.

Bakker, A.B., E. Demerouti, and W. Verbeke. 2004. Using the job demands-resources model to predict burnout and performance. Human Resource Management 43 (1): 83-104. https://doi.org/10.1002 /hrm.20004.

Barnett, T., G. Brown, and K. Bass. 1994. The ethical judgements of college students regarding business issues. Journal of Education for Business 69 (6): 333-338.

Blodgett, J.G., L. Chuan Lu, G.M. Rose, and S.J. Vitell. 2001. Ethical sensitivity to stakeholder interests: A cross-cultural comparison. Journal of the Academy of Marketing Science 29 (2): 190-202.

Borkowski, S., and Y. Ugras. 1992. The ethical attitudes of students as a function of age, sex and experience. Journal of Business Ethics 11 (12): 961-979.

Borkowski, S.C., and K.J. Ugras. 1998. Business students and ethics: A meta-analysis. Journal of Business Ethics 17: 1117-1127. https://doi.org/10.1023/A:1005748725174.

Cavanagh, G.F. 2009. What's good for business? America 20 (4): 20-22.

Cazan, A.-M. 2015. Learning motivation, engagement and burnout among university students. Procedia Social and Behavioral Sciences 187: 413-417. https://doi.org/10.1016/j.sbspro.2015.03.077.

Christensen, A.L., J. Cote, and C.K. Latham. 2016. Insights regarding the applicability of the defining issues test to advance ethics research with accounting Students: A Meta-analytic Review. Journal of Business Ethics. https://doi.org/10.1007/s10551-014-2349-7.

Chung, K. Y., Eichenseher, J. W., \& Taniguchi, T. (2008). Ethical perceptions of business students: Differences between East Asia and the USA and among "confucian" cultures. Journal of Business Ethics, 79(1-2), 121-132. https://doi.org/10.1007/s10551-007-9391-7.

Cohen, Jeffrey R., L.W. Pant, and D.J. Sharp. 1993. A validation and extension of a multidimensional ethics scale. Journal of Business Ethics 12 (1): 13-26. https://doi.org/10.1007/BF01845782.

Cohen, J.R., L.W. Pant, and D.J. Sharp. 2001. An examination of differences in ethical decision-making between Canadian business students and accounting professionals. Journal of Business Ethics 30 (4): 319-336. 
Cokley, K.O. 2000. Examining the validity of the academic motivation scale by comparing scale construction to self-determination theory. Psychological Reports 86 (2): 560. https://doi.org/10.2466/PR0.86.2.560564.

Colby, A., L. Kohlberg, J. Gibbs, and M. Lieberman. 1983. A longitudinal study of moral judgment. Monographs of the Society for Research in Child Development 48 (1): 1-124.

Cole, B.C., and D.L. Smith. 1996. Perceptions of business ethics: Students vs. business people. Journal of Business Ethics 15 (8): 889-896. https://doi.org/10.1007/BF00381856.

Cook, M.D., M.K. Holt, and C. Reagan. 2014. Preparing more than number crunchers: Incorporating corporate social responsibility and ethics in graduate business programs. Journal of Management and Sustainability 4 (4): 1-5. https://doi.org/10.5539/jms.v4n4p32.

Cormier, D., and M. Magnan. 2017. Does a firm's exposure to ethical failures matter to financial markets? A governance perspective. Journal of Management and Governance 21 (2): 267-289. https://doi. org/10.1007/s10997-016-9341-9.

Crane, A., and D. Matten. 2016. Business ethics: Managing corporate citzenship and sustainability in the age of globalisation. 4th ed. Oxford University Press.

Dean, K.L., J.M. Beggs, and T.P. Keane. 2010. Mid-level managers, organizational context, and (un) ethical encounters. Journal of Business Ethics 97 (1): 51-69. https://doi.org/10.1007/s10551-010-0495-0.

Deci, E.L., and R.M. Ryan. 1985. Intrinsic motivation and self-determination in human behavior. Plenum.

Drover, W., J. Franczak, and R.F. Beltramini. 2012. A 30-year historical examination of ethical concerns regarding business ethics: Who's concerned? Journal of Business Ethics 111 (4): 431-438. https://doi. org/10.1007/s10551-012-1214-9.

Dyrbye, L.N., M.R. Thomas, and T.D. Shanafelt. 2006. Systematic review of depression, anxiety, and other indicators of psychological distress among U.S. and. Canadian Medical Students. 81 (4): 354-373.

Emerson, T.L.N., S.J. Conroy, and C.W. Stanley. 2007. Ethical attitudes of accountants: Recent evidence from a practitioners' survey. Journal of Business Ethics 71 (1): 73-87. https://doi.org/10.1007/s10551-0069125-2.

Ethics Resource Center. (1994). Ethics in American business: Policies, Programs and Perceptions. Ethics Resource Center.

Eweje, G., and M. Brunton. 2010. Ethical perceptions of business students in a New Zealand university: Do gender, age and work experience matter? Business Ethics 19 (1): 95-111. https://doi.org/10.1111/j.14678608.2009.01581.x.

Fairchild, A.J., S.J. Horst, S.J. Finney, and K.E. Barron. 2005. Evaluating existing and new validity evidence for the academic motivation scale. Contemporary Educational Psychology 30 (3): 331-358. https://doi. org/10.1016/j.cedpsych.2004.11.001.

Ferraro, F., J. Pfeffer, and R.I. Sutton. 2005. Economics language and assumptions: How theories can become self-fulfilling. Academy of Management Review 30 (1): 8-24.

Floyd, L.A., F. Xu, R. Atkins, and C. Caldwell. 2013. Ethical outcomes and business ethics: Toward improving business ethics education. Journal of Business Ethics 117 (4): 753-776. https://doi. org/10.1007/s10551-013-1717-z.

Fritzche, D.J. 2005. Business ethics: A global and managerial perspective. 2nd ed. Irwin: McGraw-Hill.

Fritzsche, D.J., and H. Becker. 1983. Ethical Behavior of Marketing Managers. 2: 291-299.

Galbraith, S., H.B. Stephenson, and H.B. Stephenson. 1993. Decision rules used by male and female business students in making ethical value judgments: Another look. Source Journal of Business Ethics 12 (3): $227-$ 233.

Garcia-Campayo, J., M. Navarro-Gil, E. Andrés, J. Montero-Marin, L. López-Artal, and M.M.P. Demarzo. 2014. Validation of the Spanish versions of the long (26 items) and short (12 items) forms of the selfcompassion scale (SCS). Health and Quality of Life Outcomes 12 (1): 1-9. https://doi.org/10.1186/14777525-12-4.

Gelfand, S.D. 2016. Using insights from applied moral psychology to promote ethical behavior among engineering students and professional engineers. Science and Engineering Ethics 22 (5): 1513-1534. https://doi.org/10.1007/s11948-015-9721-6.

George, D., \& Mallery, P. (2003). SPSS for windows step by step. Allyn \& Bacon.

Gift, M.J., P. Gift, and Q. Zheng. 2013. Cross-cultural perceptions of business ethics: Evidence from the United States and China. Journal of Business Ethics 114 (4): 633-642. https://doi.org/10.1007/s10551013-1709-z.

Gilligan, C. (1982). In a different voice: Psychological theory and women's development. Harvard University Press.

Gino, F., and D. Ariely. 2012. The dark side of creativity: Original thinkers can be more dishonest. Journal of Personality and Social Psychology 102 (3): 445-459. https://doi.org/10.1037/a0026406. 
Gino, F., and S. Shalvi. 2015. Editorial overview : Morality and ethics: New directions in the study of morality and ethics. Current Opinion in Psychology 6: v-viii.

Grimes, P.W. 2012. Dishonesty in academics and business: A cross-cultural evaluation of student attitudes. Journal of Business Ethics 49 (3): 273-290.

Hair, J.F., R.E. Anderson, R.L. Tatham, and W.C. Black. 1998. Multivariate data analysis. 5th ed Prentice Hall.

Hansen, R.S. 1992. A multidimensional scale for measuring business ethics: A purification and refinement. Journal of Business Ethics 11: 523-534. https://doi.org/10.1007/BF01845906.

Hanson, W.R., J.R. Moore, C. Bachleda, A. Canterbury, and C. Schreiber. 2017. Theory of moral development of business students: Case studies in Brazil, North America, and Morocco. Academy of Management Learning \& Education 16 (3): 393-414. https://doi.org/10.5465/amle.2014.0312.

Haski-Leventhal, D., M. Pournader, and A. McKinnon. 2017. The role of gender and age in business students' values, CSR attitudes, and responsible management education: Learnings from the PRME international survey. Journal of Business Ethics 146: 219-239. https://doi.org/10.1007/s10551-015-2936-2.

Ho, S.S.M., A.Y. Li, K. Tam, and F. Zhang. 2015. CEO gender, ethical leadership, and accounting conservatism. Journal of Business Ethics 127: 351-370. https://doi.org/10.1007/s10551-013-2044-0.

Holland, D., and C. Albrecht. 2013. The worldwide academic field of business ethics: Scholars' perceptions of the Most important issues. Journal of Business Ethics 117 (4): 777-788. https://doi.org/10.1007/s10551013-1718-y.

Hunt, S.D., and S.J. Vitell. 1986. A general theory of marketing ethics. Journal of Macromarketing 6: 5-16.

Hyman, M.R. 1996. A critique and revision of the multidimensional ethics scale. Journal of Empirical Generalisations in Marketing Science 1: 1-35.

Jones, T. (1991). Ethical decision making by individuals in organizations: An issue-contingent model Academy of Management Review 16 (2), p366-395.

Jung, I. 2009. Ethical judgments and behaviors: Applying a multidimensional ethics scale to measuring ICT ethics of college students. Computers and Education 53 (3): 940-949. https://doi.org/10.1016/j. compedu.2009.05.011.

Keyko, K. 2014. Work engagement in nursing practice: A relational ethics perspective. Nursing Ethics 21 (8): 879-889. https://doi.org/10.1177/0969733014523167.

Kidwell, J., R. Stevens, and A. Bethke. 1987. Differences in ethical perceptions between male and female managers: Myth or reality? Journal of Business Ethics 6 (6): 451-457.

Knotts, T., T. Lopez, and H. Mesak. 2000. Ethical judgements of college students: An empirical analysis. Journal of Education for Business 75 (3): 158-163.

Kotera, Y., P. Adhikari, and W. Van Gordon. 2018a. The relationship between work motivation and worker profile in UK hospitality workers. International Journal of Mental Health and Addiction 16 (3): 751-763.

Kotera, Y., Conway, E., \& Van Gordon, W. (2018b). Mental health of UK university business students: Relationship with shame, motivation and self-compassion. Journal of Education for Business, 94(1), 1120. https://doi.org/10.1080/08832323.2018.1496898.

Lampe, M., and C. Engleman-Lampe. 2012. Mindfulness-based business ethics education. Academy of Educational Leadership Journal 16 (3): 99-111.

Leavitt, K., S.J. Reynolds, C.M. Barnes, P. Schilpzand, and S.T. Hannah. 2012. Different hats, different obligations: Plural occupational identities and situated moral judgments. Academy of Management Journal. https://doi.org/10.5465/amj.2010.1023.

Lin, C., Y. Ho, and K. Jen. 2008. An examination of cultural differences in ethical decision making using the multidimensional ethics scale. Social Behavior \& Personality 36 (9): 1213-1222.

Longenecker, J.G., J. McKinney, and C.W. Moore. 1988. The ethical issue of international bribery: A study of attitudes among US business professionals. Journal of Business Ethics 7 (5): 341-346.

Loo, R. 2004. Support for Reidenbach and Robin's (1990) eight-item multidimensional ethics scale. Social Science Journal 41 (2): 289-294. https://doi.org/10.1016/j.soscij.2004.01.020.

Lovibond, S. H., \& Lovibond, P. F. (1995). Manual for the depression anxiety stress scales (2nd ed.). Psychology Foundation.

Lund, D.B. 2000. An empirical examination of professionals' ethical marketing behavior in differing situations. Journal of Business Ethics 24 (4): 331-342.

Maslach, C., W.B. Schaufeli, and M.P. Leiter. 2001. Job burnout. Annual Review of Psychology 52: 397-422. https://doi.org/10.1146/annurev.psych.52.1.397.

Matten, D., and J. Moon. 2004. Corporate social responsibility education in Europe. Journal of Business Ethics 54 (4): 323-337.

McCabe, D.L., K.D. Butterfield, and L.K. Trevino. 2006. Academic dishonesty in graduate business programs: Prevalence, causes and proposed action. Academy of Management Learning 5 (3): 294-305. 
McDonald, G. 2004. A case example: Integrating ethics into the academic business curriculum. Journal of Business Ethics 54 (4): 371-384.

McDonald, G., and G. Donleavy. 1995. Objections to the teaching of business ethics. Journal of Business Ethics 14 (10): 839-853.

McMahon, J.M., and R.J. Harvey. 2007. Psychometric properties of the Reidenbach-Robin multidimensional ethics scale. Journal of Business Ethics 72 (1): 27-39. https://doi.org/10.1007/s10551-006-9153-y.

Mental Health Foundation. 2016. Fundamental facts about mental health 2016. London: Mental Health Foundation.

Neff, K.D. 2003. The development and validation of a scale to measure self-compassion. Self and Identity 2 (3): 223-250. https://doi.org/10.1080/15298860309027.

Nguyen, N.T., and M.D. Biderman. 2008. Studying ethical judgments and behavioral intentions using structural equations: Evidence from the multidimensional ethics scale. Journal of Business Ethics 83 (4): 627-640. https://doi.org/10.1007/s10551-007-9644-5.

O'Brien, R.M. 2007. A caution regarding rules of thumb for variance inflation factors. Quality and Quantity 41 (5): 673-690. https://doi.org/10.1007/s11135-006-9018-6.

Pascarella, E. T., \& Terenzini, P. T. (2005). How college affects students: A third decade of research. Jossey Bass.

Pochard, F., E. Azoulay, S. Chevret, F. Lemaire, P. Hubert, P. Canoui, M. Grassin, R. Zittoun, J.-R. le Gall, J.F. Dhainaut, and S. Benoit. 2001. Symptoms of anxiety and depression in family members of intensive care unit patients: Ethical hypothesis regarding decision-making capacity. Critical Care Medicine 29 (10): 1893-1897.

Raes, F., E. Pommier, K.D. Neff, and D. Van Gucht. 2011. Construction and factorial validation of a short form of the self-compassion scale. Clinical Psychology \& Psychotherapy 18 (3): 250-255. https://doi. org/10.1002/cpp.702.

Reidenbach, R.E., and D.P. Robin. 1988. Some intial steps toward improving the measurement of ethical evaluations of marketing activities. Journal of Business Ethics 7: 871-879.

Reidenbach, R.E., and D.P. Robin. 1990. Toward the development of a multidimensional for improving evaluations of business ethics. Journal of Business Ethics 9 (8): 639-653. https://doi.org/10.1007 /BF00383391.

Rest, J. R. (1986). Moral development: Advances in research and theory. Praeger Press.

Ruegger, D., and E. King. 1992. A study of the effect of age and gender upon student business ethics. Journal of Business Ethics 11 (3): 179-186.

Schaufeli, W. B., \& Bakker, A. B. (2003). Utrecht work engagement scale. Occupational Health Psychology Unit Utrecht University, December, 1-60. https://doi.org/10.1037/t01350-000.

Schaufeli, W.B., I.M. Martínez, A.M. Pinto, M. Salanova, and A.B. Bakker. 2002. Burnout and engagement in university students. Journal of Cross-Cultural Psychology 33 (5): 464 481. https://doi.org/10.1177 /0022022102033005003.

Schreiber, J.B., A. Nora, F.K. Stage, E.A. Barlow, J. King, A. Nora, and E.A. Barlow. 2006. Reporting structural equation modeling and confirmatory factor analysis results : A review. The Journal of Educational Research 99 (6): 232-338. https://doi.org/10.3200/JOER.99.6.323-338.

Seppälä, P., S. Mauno, T. Feldt, J. Hakanen, U. Kinnunen, A. Tolvanen, and W. Schaufeli. 2009. The construct validity of the Utrecht work engagement scale: Multisample and longitudinal evidence. Journal of Happiness Studies 10 (4): 459-481. https://doi.org/10.1007/s10902-008-9100-y.

Serwinek, P.J. 1992. Demographic and related differences in ethical views among small businesses. Journal of Business Ethics 11 (7): 555-566.

Sezer, O., F. Gino, and M.H. Bazerman. 2015. Ethical blind spots: Explaining unintentional unethical behavior. Current Opinion in Psychology 6: 77-81. https://doi.org/10.1016/j.copsyc.2015.03.030.

Siu, O.L., A.B. Bakker, and X. Jiang. 2014. Psychological capital Among University students: Relationships with study engagement and intrinsic motivation. Journal of Happiness Studies 15 (4): 979-994. https://doi.org/10.1007/s10902-013-9459-2.

Smyth, M.L., and J.R. Davis. 2004. Perceptions of dishonesty among two-year college students: Academic versus business situations. Journal of Business Ethics 51 (1): 63-73. https://oi.org/10.1023 /B:BUSI.0000032347.79241.3c.

Subar, A.F., L.S. Freedman, J.A. Tooze, S.I. Kirkpatrick, C. Boushey, M.L. Neuhouser, F.E. Thompson, N. Potischman, P.M. Guenther, V. Tarasuk, J. Reedy, and S.M. Krebs-Smith. 2015. Addressing current criticism regarding the value of self-report dietary data. Journal of Nutrition 145 (12): 2639-2645. https://doi.org/10.3945/jn.115.219634. 
Swanson, D.L., and D.G. Fisher. 2008. Business ethics education: If we don't know where we're going, any road will take us there. In Advancing Business Ethics (pp. 1-23), ed. D.L. Swanson and D.G. Fisher. Information Age Publishing.

Tenbrunsel, A.E., and D. Chugh. 2015. Behavioral ethics: A story of increased breadth and depth. Current Opinion in Psychology 6: 205-210. https://doi.org/10.1016/j.copsyc.2015.08.022.

Tsalikis, J., and M. Ortiz-Buonafina. 1990. Ethical beliefs' differences of males and females. Journal of Business Ethics 9 (6): 509-519.

Vallerand, R.J., L.G. Pelletier, M.R. Blais, N.M. Briere, C. Senecal, and E.F. Vallieres. 1992. The academic motivation scale: A measure of intrinsic, extrinsic, and amotivation in education. Educational and Psychological Measurement 52 (4): 1003-1017. https://doi.org/10.1177/0013164492052004025.

van Prooijen, A.M., and N. Ellemers. 2015. Does it pay to be moral? How indicators of morality and competence enhance organizational and work team attractiveness. British Journal of Management 26 (2): 225-236. https://doi.org/10.1111/1467-8551.12055.

Walker, L.J., B. de Vries, and S.D. Trevethan. 1987. Moral stages and moral orientations in real-life and hypothetical dilemmas. Child Development 58 (3): 842-858.

Wang, L., D. Malhotra, and J.K. Murnighan. 2011. Economics education and greed. Academy of Management Learning and Education 10 (4): 643-660.

Waples, E.P., A.L. Antes, S.T. Murphy, S. Connelly, and M.D. Mumford. 2009. A meta-analytic investigation of business ethics instruction. Journal of Business Ethics 87 (1): 133-151. https://doi.org/10.1007 /s10551-008-9875-0.

Whitley, B. E., \& Keith-Spiegel, P. (2001). Academic dishonesty: An educator's guide. Lawrence Erlbaum.

Wickramasinghe, N.D., D.S. Dissanayake, and G.S. Abeywardena. 2018. Validity and reliability of the Utrecht work engagement scale-student version in Sri Lanka. BMC Research Notes 11 (1): 1-6. https://doi.org/10.1186/s13104-018-3388-4.

Wright, T.A. 2004. When a student blows the whistle (on himself): A personal experience essay on "delayed" integrity in a classroom setting. Journal of Management Inquiry 13: 289-303.

Wright, T.A. 2015. Distinguised scholar invited essay reflections on the role of character in business education and student leadership development. Journal of Leadership \& Organisational Studies 22: 253-264.

Publisher's note Springer Nature remains neutral with regard to jurisdictional claims in published maps and institutional affiliations. 